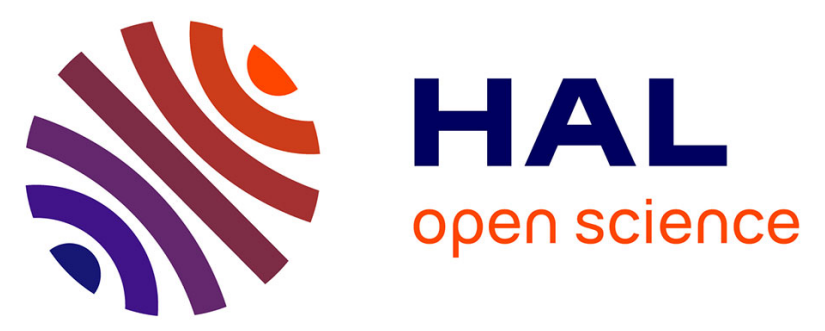

\title{
Emergent literacy skills, behavior problems and familial antecedents of reading difficulties: A follow-up study of reading achievement from kindergarten to fifth grade.
} Hugo Costa, Perdry Hervé, Soria Carmen, Pulgar Salomé, Cusin Françoise, Dellatolas Georges

\section{To cite this version:}

Hugo Costa, Perdry Hervé, Soria Carmen, Pulgar Salomé, Cusin Françoise, et al.. Emergent literacy skills, behavior problems and familial antecedents of reading difficulties: A follow-up study of reading achievement from kindergarten to fifth grade.: Behavioral problems and reading achievement. Research in Developmental Disabiltities, 2013, 34 (3), pp.1018-1035. 10.1016/j.ridd.2012.11.029 . inserm-00777289

\section{HAL Id: inserm-00777289 https://www.hal.inserm.fr/inserm-00777289}

Submitted on 17 Jan 2013

HAL is a multi-disciplinary open access archive for the deposit and dissemination of scientific research documents, whether they are published or not. The documents may come from teaching and research institutions in France or abroad, or from public or private research centers.
L'archive ouverte pluridisciplinaire HAL, est destinée au dépôt et à la diffusion de documents scientifiques de niveau recherche, publiés ou non, émanant des établissements d'enseignement et de recherche français ou étrangers, des laboratoires publics ou privés. 
Emergent literacy skills, behavior problems and familial antecedents of reading difficulties: A follow-up study of reading achievement from kindergarten to fifth grade

Hugo Câmara Costa ${ }^{1 \dagger, 2}$, Hervé Perdry PhD. ${ }^{1,3}$, Carmen Soria $\mathrm{PhD}^{2}$, Salomé Pulgar ${ }^{4}$, Françoise Cusin $\mathrm{MD}^{4}$ and Georges Dellatolas MD $\mathrm{PhD}^{1}$

${ }^{1}$ National Institute of Health and Medical Research, INSERM U669

Bâtiment Leriche (Secteur Jaune, Porte 45, 1er étage), 16 avenue Paul Vaillant Couturier 94807 Villejuif, France. Tel. 0033(0)1 455952 48; Fax. 0033 (0)1 45595331

E-mail: hugo.costa@etu.parisdescartes.fr; george.dellatolas@inserm.fr

${ }^{\dagger}$ Corresponding author

${ }^{2}$ Paris Descartes University - Université Paris Descartes, Centre Henri Piéron UFR Institut de Psychologie, 71, avenue Edouard Vaillant

92774 Boulogne-Billancourt Cedex, France. E-mail : carmen.soria@hotmail.com

${ }^{3}$ Paris-Sud University, INSERM U669 Hôpital Paul Brousse, Bâtiment Inserm 15/16

94807 Villejuif, France. E-mail: herve.perdry@gmail.com

${ }^{4}$ Academic Inspection of the Department of National Education

Inspection Académique, Cité Administrative, Boulevard Henri Dunant

71025 Mâcon, France. E-mail: salome.pulgar@gmail.com; francoise.cusin@ac-dijon.fr 


\begin{abstract}
This study examined the relation between emergent literacy skills, teachers' reports of behavioral problems, and word reading achievement in a community sample of French students. Family background was investigated and included familial antecedents of reading difficulties (Fa/Rd) and parents' educational level. The analyses explored the pattern of concurrent relations between behavioral, familial and emergent literacy measures in a sample of 812 preschoolers, and their predictive power in explaining word reading achievement in a sub-sample of 150 children followed from kindergarten to fifth grade. Word reading at fifth grade was predicted by kindergarten measures of phonological awareness and letter knowledge. Teachers' reports of inattention symptoms at each grade level were associated with early reading skills and with subsequent word reading. Fa/Rd were concurrently and longitudinally associated with emergent literacy skills, teachers' reported inattention and word reading. These results indicate that children with a family history of reading difficulties are at increased risk for the co-occurrence of reading difficulties and attention problems from kindergarten onward. These findings confirm the shared influence of $\mathrm{Fa} / \mathrm{Rd}$ on the comorbidity between inattention symptoms and reading difficulties in a non-diagnosed community sample of preschool children followed through late elementary school.
\end{abstract}

Keywords: emergent literacy skills, inattention, familial antecedents of reading difficulties, teachers' reports of behavioral problems, word reading achievement. 
Emergent literacy skills, behavior problems and familial antecedents of reading difficulties:

A follow-up study of reading achievement from kindergarten to fifth grade

\section{Introduction}

Reading acquisition is a central challenge in children's developmental trajectories and a key determinant to overall educational success during elementary school (Cunningham \& Stanovich, 1997; Duncan et al., 2007; Stanovich, 1986). As a result, children who manifest early difficulties in learning to read represent a vulnerable group at high risk of underachievement trajectories throughout childhood and beyond, with long lasting consequences and costs for individuals and societies (Campbell, Pungello, Miller-Johnson, Burchinal \& Ramey, 2001; Heckman, 2006; Maughan et al., 2009).

The concept of emergent literacy postulates that the development of reading ability is associated with a range of skills displayed by the preliterate child that are considered developmental precursors of conventional forms of reading and writing, as well as the social environments that allow the emergence of these developments (Whitehurst \& Lonigan, 1998). Within the set of emergent literacy skills, the existing literature has highlighted three main constructs strongly associated with preschool children's subsequent word identification abilities: oral language skills, print knowledge and phonological processing abilities. An extensive body of research has supported the predictive value of these skills for preschoolers' later word reading outcomes (Jordan, Snow \& Porche, 2000; Lonigan, Burgess \& Anthony, 2000; Storch \& Whitehurst, 2002; Spira, Bracken \& Fischel, 2005; Wagner et al., 1997). Importantly, extant longitudinal analyses have shown that individual differences in these early literacy skills are relatively stable from kindergarten onward and contribute to later discrepancies in reading ability throughout elementary school (Billard et al., 2009; Cunningham \& Stanovich, 1997; Hecht, 
Burgess, Torgesen, Wagner \& Rashotte, 2000; Watier, Dellatolas, \& Chevrie-Muller, 2006).

Preschoolers' oral language skills, such as vocabulary knowledge and oral comprehension, were found to be powerful predictors of early and later reading achievement suggesting their crucial role in learning to read for beginning readers (Muter, Hulme, Snowling \& Stevenson, 2004; Storch \& Whitehurst, 2002; Watier et al., 2006). Print knowledge, which refers to children's understanding of the conventions of prints (e.g., knowing that writing goes from left to right and top to bottom across a page), letter names and print to sound correspondences, was shown to explain a substantial proportion of variability in the growth of reading outcomes (Hecht et al., 2000, Wagner et al., 1997). However, letter knowledge has been pointed as the most powerful single predictor of short and long-term literacy success, when compared with other aspects of print knowledge (Lonigan, Burgess \& Anthony, 2000; Muter et al., 2004; Storch \& Whitehurst, 2002). Finally, phonological awareness, the ability to explicitly represent and manipulate the sounds of language, is considered a developmental precursor of critical importance in the initial stages of reading acquisition, particularly in children's ability to decode words into their linguistic units (Hulme, Snowling, Caravolas \& Carroll, 2005; Wagner \& Torgesen, 1987, for a review). Poor readers have been consistently found to perform below the level of normal readers on phonological awareness tasks (Hecht et al., 2000; Shaywitz et al., 1999) and longitudinal studies have demonstrated its unique contribution to later reading progress during elementary school (Billard et al., 2008, 2009; Spira et al., 2005; Storch \& Whitehurst, 2002; SprengerCharolles, Siegel, Béchennec \& Serniclaes, 2003; Sprenger-Charolles, Colé, Béchennec \& Kipffer-Piquard, 2005; Torgesen, Wagner, Rashotte, Burgess \& Hecht, 1997; Wagner et al., 1997). Moreover, the relation between phonological awareness and learning to read appears to be reciprocal, as demonstrated in several studies regarding the crucial role of early reading skills in 
the acquisition of phonological awareness (de Santos Loureiro et al., 2004, Dellatolas et al., 2003). Thus, a substantial body of evidence suggests the developmental continuity between preschoolers' emergent literacy and oral language skills with later reading and word decoding abilities. As a consequence, children who fail to develop proficient levels of emergent literacy skills at preschool are at increased risk of experiencing inadequate reading abilities during elementary school (Storch \& Whitehurst, 2002; Whitehurst \& Lonigan, 1998).

In order to increase understanding of the factors that influence early academic achievement, researchers have called for a broader perspective that recognizes the importance of behavioral correlates in subsequent learning (Duncan et al., 2007; Entwisle \& Alexander, 1998). Notably, the association between reading achievement and behavior problems during early and middle childhood has been well documented (Hinshaw, 1992, for a review). Numerous studies at the preschool level have presented evidence regarding the intersection between emergent literacy skills and early behavior problems prior to school entry (Lonigan et al., 1999; Rabiner \& Coie, 2000; Spira \& Fischel, 2005, for a review; Velting \& Whitehurst, 1997). Moreover, evidence from longitudinal research has demonstrated a link between early behavior problems and academic underachievement from kindergarten to elementary school (Al Otaiba \& Fuchs, 2003; Bub, McCartney \& Willet, 2007; Dally, 2006; Hinshaw, 1992, for a review; Rabiner \& Coie, 2000; Trzesniewski, Moffit, Caspi, Taylor, \& Maughan, 2006; Vaughn, Zaragoza, Hogan \& Walker, 1993). Therefore, children who meet criteria for reading disabilities (RD) are reported to be at increased risk of comorbidity with psychiatric disorders, in particular with externalizing disorders such as Attention Deficit Hyperactivity Disorder (ADHD), both inattentive and hyperactive-impulsive subtype (Hinshaw, 1992), and Conduct Disorder (CD) (Angold, Costello \& Erkanli, 1999). However, it has been proposed that the significant overlap of RD, ADHD and 
$\mathrm{CD}$ is related with shared associations between these diagnostic entities. Indeed, reading difficulties and $\mathrm{CD}$ were shown to be unrelated except by their common correlation with the attention deficits reported in ADHD (Rapport, Scanlan \& Denney, 1999; Carroll, Maughan, Goodman \& Meltzer, 2004). Furthermore, despite the well-documented association between ADHD and reading problems (Merrell \& Tymms, 2001; Hinshaw, 1992), a growing literature has documented that it is the inattentive subtype of ADHD, when compared with the hyperactive subtype, which correlates more strongly with the reading difficulties of school-aged children (Willcutt \& Pennington, 2000a; McGee, Prior, Williams, Smart \& Sanson, 2002). Importantly, longitudinal studies have presented evidence that inattentive behavior during kindergarten predicted reading achievement by the end of elementary school (Duncan et al., 2007; Rabiner \& Coie, 2000), and that inattention reported at elementary school significantly predicted long-term educational attainment at age 22-23 (Pingault et al, 2011). In France, existing literature has revealed similar patterns concerning the association between behavior problems and reading difficulties. Inattention symptoms reported by the teacher, but not hyperactivity-impulsivity or conduct problems, were significantly related with early reading skills in preschool children (Dellatolas, Watier, Giannopulu \& Chevrie-Muller, 2006; Giannopulu, Escolano, Cusin, Citeau \& Dellatolas, 2008), and predicted reading achievement on measures of word identification and reading comprehension (Billard et al., 2010; Giannopulu et al., 2008). Although existing literature has reported a significant association between reading achievement and behavior problems on children in elementary school, the relationship between emergent literacy skills and behavioral difficulties in young children before school entry remains understudied (Doctoroff, Greer \& Arnold, 2006). In addition, longitudinal studies that examine the influence of separate dimensions of behavioral problems on emergent literacy skills and subsequent reading outcomes 
are needed, due to existing evidences presented in several studies regarding the predictive value of distinct dimensions of behavior problems, other than inattentive behavior, on reading acquisition (Bracken \& Fischel, 2007; Spira et al., 2005; Trzesniewski et al., 2006).

In addition to the significant role that emergent literacy and behavior problems play on preschoolers' later reading ability, the impact of family background on children's reading development is well established (Entwisle \& Alexander, 1998, Sénéchal \& LeFevre, 2002, Whitehurst \& Lonigan, 1998). For instance, parents' education level has been consistently associated with children's performances on measures of emergent literacy skills and with later reading performance (Billard et al., 2008; Bradley \& Corwyn, 2002; Burchinal, PeisnerFeinberg, Pianta \& Howes, 2002; Hecht et al., 2000; Watier et al., 2006). Of particular interest in this field of research is the finding that difficulties in learning to read are significantly familial: children reared in families where at least one relative had a history of RD are at increased risk of developing the disorder, when compared to children without familial antecedents of RD (Puolakanaho et al., 2007; Snowling, Gallagher \& Frith, 2003). These studies have put forward the notion of a familial risk in the development of reading difficulties, which is conventionally conceptualized as the presence of a history of RD antecedents in at least one of the child's relatives (i.e. parents and/or siblings). Moreover, these studies have highlighted that the inclusion of measures of familial antecedents of reading acquisition in screening procedures during kindergarten, in addition to measures of oral language, letter knowledge and phonological awareness, improved significantly the probability of identifying a child at risk of developing RD later on elementary school. Importantly, a study conducted by Doyen et al. (2004) extended the previous findings by demonstrating that a parsimonious screening procedure aimed to examine the presence of parental antecedents of reading difficulties was related with both lower scores on 
early literacy skills and with teachers' reports of inattention symptoms during kindergarten. This result is in line with evidences from family studies concerning the significant familial nature of RD and ADHD (Pennington et al., 2009, for a review), and concurs with the findings from a twin study regarding the shared familiality between these two disorders (Friedman, Chhabildas, Budhiraja, Willcutt \& Pennington, 2003). However, there remains a dearth of information relative to the association between familial antecedents of reading acquisition, children's emergent literacy skills and inattentive behavior before school entry, as well as its impact on subsequent reading performance at the end of elementary school in non-diagnosed samples. Therefore, as suggested by Hinshaw (1992), the present study examines the role of familial antecedents of reading acquisition as a background variable implied in the co-variation between reading achievement and behavior problems, specifically inattentive behavior. Although previous studies conducted in France have shed some light over the factors implied during reading development, longitudinal studies aimed to analyze the developmental precursors and correlates of reading acquisition are still required (INSERM, 2007). The mid-term contribution of emergent literacy skills, behavior problems and family background on the mid-term reading outcomes of French-speaking children remains to be examined in the general population.

The objectives of the present study were a) to examine the concurrent associations between emergent literacy skills, oral language, behavioral problems and familial background at kindergarten and $b$ ) to determine the predictive value of this broad constellation of factors as explanatory variables of word reading achievement at fifth grade. Additionally, this study aimed to extend previous research concerning the association of familial antecedents of reading difficulties, teachers' reports of behavioral problems and emergent literacy skills with later word reading achievement at the end of elementary school. 
For these purposes, the present study used a community-based sample drawn from a larger prospective study in a general population of French preschoolers. Some of these preschoolers would have been expected to develop reading problems during elementary school, given the reported prevalence of reading disabilities in the general population (e.g., $7.5 \%$, according to Shaywitz, Shaywitz, Fletcher \& Escobar, 1990). Information concerning children's early literacy, oral language, behavioral difficulties and familial factors was gathered during the kindergarten year, and a sub-sample of this kindergarten group was followed through the end of elementary school, where children's behavior and word reading performances were assessed at fifth grade. Furthermore, we isolated a subset of children at fifth grade whose word reading performances fell significantly below the sample mean, in order to examine how the study's kindergarten variables related with lower performances in the word reading outcome at the end of elementary school. Because significant studies have systematically shown that deficits in word identification constitute the basic source of poor reading, notably in the case of specific reading disability or dyslexia, and that measures of word reading are typically used in the study of clinically significant reading difficulties (Vellutino, Fletcher, Snowling, \& Scanlon, 2004, for a review), we are focusing on difficulties in learning to read associated with inadequate word reading efficiency in the current study.

\section{Material and methods}

\subsection{Participants}

The participants were selected from a larger ongoing prospective longitudinal study aimed to identify child and environmental factors related to learning and behavioral difficulties in a community-based sample followed from kindergarten to the end of elementary school (Callu et al., 2005; Callu, Jacquier-Roux, Cusin, Giannopulu \& Dellatolas, 2003; Giannopulu, Cusin, 
Escolano \& Dellatolas, 2007; Giannopulu, Escolano, Cusin, Citeau \& Dellatolas, 2008). This general population study began during the 2001-2002 school year and included all children aged three-six years who attended the preschools of the Creusot Montceau-les-Mines community (Saône-et-Loire) in the central-east region of France. A total of 48 preschools that served families from socioeconomically diverse backgrounds were enrolled in the study. As required by ethical imperatives, parents and school administrators were contacted and invited to participate in the study and informed consent was obtained in order to conduct this research.

The data presented here spanned a six-year period and refers to two samples of children derived from two school levels, kindergarten and fifth grade (see Table 1 and 2, for descriptive statistics of the study samples). The kindergarten sample was composed of all the children attending the community's preschools during the 2003-2004 school year, when children were in the final year of the preschool period, for whom we had outcome data in at least one of the study’s measures at kindergarten (parents' sociodemographic background and familial antecedents of reading difficulties questionnaire, emergent literacy skills and teachers' behavioral questionnaire). A total of 812 children, 422 boys and 390 girls, aged 5-6 years (mean 5.8 years, SD 3 months) constituted the kindergarten sample of the present study. The fifth grade sample was a subset of the kindergarten sample. Due to limited resources regarding research staff to collect data at fifth grade in the present study, a representative set of 10 elementary schools was selected across a total of 34 schools from the Creusot Montceau-les-Mines community. This selection procedure aimed to ensure the representativeness of the community's population according with the geographic area of implementation of each elementary school and its suburban or rural condition. For each of the selected elementary schools, data on reading performance and teachers' behavioral reports was collected for all children enrolled in fifth grade 
classrooms during the 2008-2009 school year. To be included in the fifth grade sample, children were required to a) be part of the kindergarten sample during the 2003-2004 school year, and b) to have outcome data in at least one of the study measures at fifth grade (reading performance or teachers' behavioral reports). From the initial kindergarten sample of 812 children, 19\% had outcome data on reading performance and $14 \%$ had data on teachers' behavioral reports at fifth grade. This resulted in a fifth grade sample composed of 150 students, 77 boys and 73 girls, with ages ranging from 10 to 11 years old (mean 10.7 year, SD 3 months). The resulting samples were composed of children from diverse sociocultural backgrounds of a general population of suburban and rural communities in France. Note however that the participants in the present community-based study do not constitute a nationally representative sample since children from large urban areas were absent. All participants attended general education classrooms and there were no gender differences in the group composition of the kindergarten and fifth grade samples. Only $5 \%$ of the parents reported being of a different nationality other than French, and no significant differences between and within samples were found when parents' nationality was taken into account.

\subsection{Procedure}

Data collection began during the final year of the preschool period. Behavioral and cognitive assessment was conducted with all children enrolled in the preschools included in our study. Through collaboration with school medical staff, parents were assigned questionnaires concerning sociodemographic and familial characteristics, and teachers completed questionnaires regarding children's classroom behavior at preschool. Concomitantly, school doctors conducted a health check exam. In France, it is standard procedure to perform a systematic examination of all children aged between five and six years old that are enrolled in kindergarten. This 
examination includes a visual and audition exam, as well as the assessment of cognitive and language development. All measures were obtained between January and June in the 2003-2004 school year. At fifth grade, cognitive assessment occurred during the spring semester of the 2008-2009 school year. All measures were individually administered in one session per child by trained staff of the research team. In addition, teachers were asked to complete a questionnaire concerning children's classroom behavior and reports were collected during the same period of the cognitive assessment. Fifth grade teachers were unaware of the results of the cognitive and behavioral testing performed at kindergarten.

\subsection{Measures}

2.3.1. Kindergarten assessment (2003-2004 school year). Parents were asked to provide background information relative to their families by means of questionnaires. These included questions concerning parents' level of education, defined as the final school grade completed by each parent, as well as information concerning familial reading acquisition background, such as the presence of difficulties in learning to read in any of the child's siblings.

Familial antecedents of reading difficulties. Parents completed a questionnaire aimed at examining the presence of reading-related difficulties during their childhood. Each parent was asked to respond separately to the following question: "During your childhood did you manifest one or several of the following problems that frequently worried your parents or teachers: (1) “difficulties in expressing yourself orally or making yourself understand"; and (2) "difficulties in learning to read". Each of these items was scored zero (no) or one (yes). Note that the generic term "reading difficulties" includes parental reports of oral language difficulties.

Because the purpose of the present study was to identify the presence or absence of a history of reading difficulties in children's family, we considered simultaneously parents' 
responses to this questionnaire as well as their responses to the familial background questionnaire regarding the presence of reading difficulties in at least one of the child's siblings. In this way, familial antecedents of reading difficulties were defined as a binary variable in which at least one of the parents reported the presence of oral or written language difficulties in one of the members of the family (i.e., the parents and/or the siblings) or not.

BSEDS (Bilan de Santé: Evaluation du Développement pour la Scolarité de 5 à 6 ans). The BSEDS battery ([Health Examination: School Developmental Assessment for Children aged 5-6 years], Zorman \& Jacquier-Roux, 2001) is a standardized screening instrument widely used with French preschool population that assesses children's cognitive, motor and social development. For the purpose of the current study, nine subtests were selected from the large collection of tasks that compose this battery, namely: Rhyme identification (8 items), Syllabic counting (5 items), Syllabic deletion (10 items), Vocabulary (15 items), Pseudoword repetition (10 items), Oral comprehension (8 items), Letter reading (12 items), Sentence repetition (16 items) and Figure reproduction (6 items); for further details see Giannopulu et al. (2008). These subtests were chosen based on their psychometric soundness and evidence that these measures of emergent literacy and language skills predict later reading acquisition and allow for the early identification of children at risk of developing later reading difficulties (Zorman \& JacquierRoux, 2001).

2.3.2. Fifth grade assessment (2008-2009 school year). The assessment performed at fifth grade included the l'Alouette reading test (Lefavrais, 2006), the ODEDYS battery (Outil de Dépistage des Dyslexies - Version 2 [Dyslexia Screening Instrument - Version 2], JacquierRoux, Valdois \& Zorman, 2002) and the teachers' behavioral questionnaire. The l'Alouette is a standardized reading test commonly used by clinicians and researchers in France to identify 
children that exhibit reading difficulties. This instrument assesses children's reading fluency and accuracy and provides a standardized reading age according with the child's chronological age or school level. The ODEDYS battery allowed us to assess the word reading outcome at fifth grade by means of a large span of reading and spelling tasks. For the purpose of the present study, eight subtests from the ODEDYS battery were considered in addition to the l'Alouette: Word Reading (Irregular, Regular and Pseudoword Reading), Word Dictation (Irregular, Regular and Pseudoword Dictation) and Sentence Dictation (Accordance and Use Sentences). The selection of these subtests was based on their reported reliability and sensitivity to identify children with reading difficulties at the end of the elementary school (Jacquier-Roux, Valdois \& Zorman, 2002). Moreover, these selected subtests represent the components of the ODEDYS battery aimed to assess the ability to read words at the end of elementary school.

L'Alouette. In this test, the child has to read a 265-word text as quickly and as accurately as possible. The text is composed of rare words, as well as some spelling and semantic traps, and reading comprehension is not taken into account. The child has three minutes to complete the task. The total score corresponds either to the number of correct words read in three minutes or to the reading time (if fewer than three minutes), once the number of errors is computed. This score is then converted into a standardized reading age that spans from six to 16 years.

Word reading (irregular, regular and pseudoword reading). In this task, the child was provided a list of 20 irregular, 20 regular and 20 pseudowords and was asked to read each list of words as quickly as possible. A score of one was attributed for each word correctly read and three scores were generated, one for words, one for irregular words and another for pseudowords $(\max =20$ for each set of words). In addition, children's reading speed was recorded as the 
number of seconds required to read each of the lists of regular, irregular and pseudowords. This scoring system yielded a minimum and maximum score of 37 and 188 seconds, respectively.

Word dictation (irregular, regular and pseudoword dictation). This task evaluates children's phonological and orthographic ability. Three sets of 10 irregular, 10 regular and 10 pseudowords each were presented orally to the child. The child was required to write each of the presented words. The total score was the number of words correctly written and three scores were generated for each set of 10 words ( $\max =10$ for each category of words). For pseudowords, a correct answer was also attributed if a child presented an orthographic form that was phonologically correct (ex. «nagul », « nagule », « nagulle »= one point).

Sentence dictation (use and accordance sentences). The child was required to write a text composed of five sentences. The main aim of this task was to measure the phonological and orthographic processing of two sets of 10 words each, according to their spelling accuracy (use sentences) and grammatical accordance (accordance sentences). The total score was the sum of the correct answers for each set of 10 words ( $\max =10$ for use sentences and $\max =10$ for accordance sentences).

\subsubsection{Common assessment at kindergarten and fifth grade.}

Teachers' behavioral questionnaire. Teachers completed a 21-item questionnaire used to assess children's classroom behaviors during preschool and fifth grade. Each item stated a particular behavior (e.g. "the child can't concentrate") and was rated on a three-point scale to denote whether the child displayed the particular behavior (i.e., 0 - no, 1 - sometimes, 2 - yes). A previous study conducted by Giannopulu and colleagues (2008) has reported the usefulness of this questionnaire as a screening instrument for the identification of behavioral problems by the classroom teachers. Therefore, according with the methodology employed in the 
abovementioned study, we performed a principal component analysis of the 21 questions of the questionnaire at kindergarten and at fifth grade. Four factors were defined and each factor was composed of four questions. These factors were named according to the specificity of the questions they were based on, namely: F1, 'hyperactivity'; F2, 'inattention'; F3, 'conduct problems' and F4, 'unsociability'. We generated new variables, one for each factor, by summing up the teachers' answers to the questions that composed each specific factor. These four factors accounted for $61 \%$ of the variance in the teachers' behavioral reports at kindergarten and for $64 \%$ at fifth grade. The internal consistency of each factor was good with Cronbach's alpha values of $.87, .82, .78, .74$ at kindergarten, and $.87, .81, .80, .63$ at fifth grade for 'hyperactivity', 'inattention', 'conduct problems' and 'unsociability', respectively.

\subsection{Data reduction and design of statistical analysis}

The statistical analyses were conducted with the SAS 9 software ${ }^{\circledR}$ (SAS, Institute Inc. Cary, NC, USA). For the purpose of the present study we generated a BSEDS global score by summing the standard scores obtained in all the nine subtests administered from the BSEDS battery. Reliability for the BSEDS global score was good (Cronbach's alpha reliability $=.78$ ). Similarly, given the multiple measures derived from the ODEDYS battery at fifth grade, we aimed to combine them into a composite score of word reading in order to increase reliability and reduce the number of comparisons. For this purpose, we began by combining the standard scores of the three word reading subtests, the reading speed scores for each of the word reading subtests, and the five dictation subtests of words and sentences, into three aggregated measures, respectively. Correlation analysis procedures were then performed to examine the pattern of concurrent relations between these three aggregated measures together with the remaining subtests of the ODEDYS battery. The three aggregated scores were substantially correlated 
among each other $(\mathrm{r}>.50, \mathrm{p}<.001$, in all cases $)$, but were only weakly correlated with the remaining subtests of the ODEDYS battery. Subsequently, we conducted a principal component analysis of these aggregated measures and all the subtests from the ODEDYS battery. The first factor was composed of these three aggregated measures and accounted for $70 \%$ of the variance in the ODEDYS overall performance at fifth grade (the factor loadings of these aggregated measures were $.86, .82$ and .83 for the word reading score, the word reading speed and the dictation score, respectively). Therefore, we considered it appropriate to combine them into a composite score. Raw scores of the tasks that composed each of the three aggregated measures were transformed into z scores and we generated a normally distributed composite score by summing the $\mathrm{z}$ scores across these three measures. Hence, the word reading composite score represents the combination of eight subtests from the ODEDYS battery, as well as children's reading speed in the word reading subtests. Note that this "word reading" composite includes the scores of spelling tasks. Reliability of this composite was good (Cronbach's alpha reliability $=$ .78) and its correlation with l'Alouette, a standardized measure of reading fluency and accuracy, was high $(\mathrm{r}=.77, \mathrm{p}<.001)$. Consequently, only this composite score was taken into account in the present study as the word reading outcome at fifth grade. In addition, we used this composite score to discriminate children experiencing reading difficulties and normal readers at fifth grade. Children who evidenced significantly lower performances on the word reading outcome at fifth grade (defined by a cut off score of one standard deviation below the sample mean) were defined as a reading difficulties group, while children whose performances were above this cut off score composed the normal readers group. This cut off point selected approximately $11 \%$ of the fifth grade sample, a prevalence that is congruent with estimates from epidemiological studies (Fluss et al., 2008; Watier et al., 2006). 
In our data analysis, we used chi-square tests and independent-samples t tests at each grade level to uncover any differences within the kindergarten and the fifth grade sample according with all the study measures. In addition, these same procedures were used to perform group comparisons between the kindergarten and the fifth grade sample, as well as between children with lower word reading performances at fifth grade, defined as a reading difficulties group, and normal readers at the same school period.

The teachers' behavioral questionnaire was analyzed through concurrent and longitudinal correlation analysis procedures (CORR procedure). The concurrent analyses assessed the association between teachers' reported behavioral problems, children's cognitive skills and familial factors at kindergarten, as well as the relation between teacher's behavioral reports and word reading at fifth grade. The longitudinal analyses included the correlation of teachers' factors at preschool with word reading at fifth grade, and the correlation among the teachers' factors from kindergarten to fifth grade.

Finally, linear regressions (REG and GLM procedures of SAS) were used to examine the concurrent contributions of familial antecedents of reading difficulties and teachers' behavioral factors in the prediction of the BSEDS overall score at kindergarten, as well as to test for the longitudinal effects of these variables in the word reading outcome at fifth grade, while controlling for the effects of children's emergent literacy skills. These regression analyses allow to estimate the degree to which the aforementioned variables (predictors) explained independent variance (type III sum of squares) in children's outcomes at kindergarten (BSEDS score) and at fifth grade (ODEDYS score). Only the measures significantly related with children's outcomes at kindergarten and at fifth grade were considered for inclusion in the regression analyses. It should be mentioned that, in these regression analyses, we adjusted for the potential effects of 
background demographic confounds, namely gender and parents' level of education. In addition, we controlled for the effects of the months of testing of the emergent literacy skills at kindergarten (from January to June). For parents' educational level, we generated a binary variable defining whether none or at least one of the parents had obtained a high school diploma and we included this variable in the regression analyses.

\section{Theory}

$<$ Insert Figure 1 here >

The general conceptual model (see Figure 1) presents the hypothesized relationships among emergent literacy skills, oral language, behavior problems, familial antecedents of reading difficulties and word reading achievement from kindergarten to fifth grade. According with the literature, preschoolers' oral language and emergent literacy skills, such as phonological awareness and letter knowledge, may each facilitate the ability to read words during elementary school (Hecht et al., 2000; Lonigan, Burgess \& Anthony, 2000; Storch \& Whitehurst, 2002). In addition, inattentive behavior, when compared with other externalizing problems, has an adverse influence on the development of emergent literacy skills and contributes to the prediction of reading acquisition during elementary school (Bub et al., 2007; Dally, 2006; Rabiner \& Coie, 2000). Likewise, the presence of familial antecedents of reading difficulties is associated with measures of emergent literacy skills at kindergarten and with later word reading achievement at elementary school (Puolakanaho et al., 2007; Snowling, Gallagher \& Frith, 2003). A new component of Figure 1 that has been added in this model is the association of familial antecedents of reading difficulties with teachers' behavioral reports of inattention symptoms at 
kindergarten and at the end of elementary school. This assumption is based on a previous study regarding the concurrent association found during kindergarten among parental antecedents of reading difficulties, early literacy skills and teachers' reports of inattention symptoms (Doyen et al., 2004). In addition, evidence suggests that school-aged children that exhibited a family history of reading difficulties were more likely to manifest attention-deficit disorder without hyperactivity (ADD/WO; Hynd, Lorys, Semrud-Clikeman \& Nieves, 1991). More recently, twin studies have advanced the argument of shared familiality between RD and ADHD (Friedman et al., 2003) and underscored that the association between inattention and reading is in place from kindergarten onwards and is partially attributable to common genetic and environmental influences (Ebejer et al., 2010; Paloyelis, Rijsdijk, Wood, Asherson \& Kuntsi, 2010; Willcutt et al., 2007). Therefore, it is proposed that the presence of familial antecedents of reading difficulties will be associated with emergent literacy skills, teachers' reports of inattention symptoms, and word reading from kindergarten to fifth grade. The hypotheses of the current study were that:

1. Teachers' reports of attention problems would be substantially and consistently associated with measures of emergent literacy skills in kindergarten and with word reading at fifth grade, when compared with teachers' reports of hyperactivity, conduct problems and unsociability;

2. Children whose parents reported antecedents of reading difficulties in the family would obtain a higher frequency of teachers' reports of attention problems and lower performances on measures of reading-related skills in kindergarten and in fifth grade, when compared with children without a family history of difficulties in learning to read; 
3. Word reading at fifth grade would be best predicted by kindergarten measures of emergent literacy skills. Family history of reading difficulties, teachers' reports of attention problems, and emergent literacy skills at kindergarten would contribute independently to the prediction of the word reading outcome.

\section{Results}

\subsection{Descriptive statistics and preliminary analyses}

Demographic and descriptive statistics for all measures at kindergarten and fifth grade are presented in Table 1 and 2. It is informative to note that the number of observations (N) available for some of the study's variables differed according with the assessment measures used to collect data at kindergarten and at fifth grade. Therefore, due to the presence of missing data for some of the participants in the present study, the data analysis here reported was based on the total of participants that presented complete data in each of the measures included in the statistical analyses described subsequently.

As previously mentioned, reliabilities for the teachers questionnaire, the BSEDS battery and the ODEDYS word reading composite score were in the acceptable range. Performances in the BSEDS subtests were free from floor and ceiling effects on almost all tasks, with the exception of modest ceiling effects on two of the dictation tasks. However, there was sufficient variability on these measures to allow us to examine their association with the word reading outcome and the behavioral variables. We begin by presenting the results of the cross sectional analysis of the study's variables at kindergarten and at the fifth grade school period.

Subsequently, we report the results of the longitudinal analysis performed between the teachers' behavioral questionnaire from kindergarten to the fifth grade, and we indicate the relative contribution of each of the study variables to the prediction of the word reading outcome at fifth 
grade. Finally, we present the results of the group comparisons performed between the group of children defined as experiencing reading difficulties and normal readers.

< Insert Table 1 and 2 here >

In order to examine group differences between the participants followed and nonfollowed from kindergarten through fifth grade, chi-square and t test comparisons were conducted for all the study's variables. Results of these analyses are summarized in Table 3 and 4. The group followed through fifth grade contained a significantly higher proportion of students whose at least one parent had a high school diploma, than the kindergarten group. Students in the non-followed group came from families with a significantly higher proportion of parents that reported reading difficulties in the family, as compared to students in the fifth grade group. Moreover, $\mathrm{t}$ test comparisons revealed that children followed from kindergarten through fifth grade obtained significantly higher global scores in the BSEDS battery and a lower proportion of 'unsociability' symptoms reported by the teacher, than the non-followed group. However, both groups were equivalent concerning gender and teachers' reports of hyperactivity', 'inattention' and 'conduct problems'. The significant differences found between the groups of participants followed and non-followed through fifth grade may be partially explained by grade retention (i.e. two subsequent years at the same grade) of some students with academic difficulties from kindergarten onwards. In the French educational system, children showing low educational achievement can be retained throughout the course of elementary school. Therefore, students retained during elementary school were not in fifth grade during the school year where data collection took place. Preschoolers with lower performances on the measures of early reading 
skills and whose parents had lower educational levels presented a significantly higher probability of being retained during elementary school, due to the often-cited influence of these variables on children's school achievement (for a review, see Duncan et al., 2007). Hence, grade level retention of participants from kindergarten to fifth grade contributed to the sample attrition observed between the two grade levels and provides a plausible justification for the overrepresentation of children in the fifth grade sample with better cognitive resources and a family background characterized by a higher educational level of the parents.

< Insert Table 3 and 4 here >

\subsection{Cross sectional analyses}

\subsubsection{Correlations among factors of the teachers' behavioral questionnaire at}

kindergarten and at fifth grade. To assess the concurrent association among the four factors derived from the teachers' behavioral questionnaire, correlation analyses were conducted both within the kindergarten and the fifth grade sample. Results in the kindergarten period indicated that teachers' behavioral reports were all significantly associated with each other at the .001 level. Teachers' reports of 'hyperactivity' were significantly correlated with 'inattention' ( $\mathrm{r}=$ $.51)$, 'conduct problems' $(r=.55)$ and unsociability' $(r=.52)$. Furthermore, teachers' reports of 'conduct problems' correlated significantly with 'unsociability' $(\mathrm{r}=.52)$, and 'inattention' was correlated both with 'conduct problems' $(\mathrm{r}=.39)$ and 'unsociability' $(\mathrm{r}=.41)$.

This pattern of results between teachers' reports of behavioral difficulties was reproduced at the fifth grade level. Hence, teachers' reported 'hyperactivity' was significantly correlated with 'inattention' $(r=.49, \mathrm{p}<.0001)$, 'conduct problems' $(r=.45, \mathrm{p}<.0001)$ and unsociability' 
$(\mathrm{r}=.53, \mathrm{p}<.0001)$. In addition, results indicated a statistically significant relationship between teachers' reports of 'conduct problems' and 'unsociability' $(r=.45, \mathrm{p}<.001)$, as well as between teachers' reports of 'inattention' and 'conduct problems' $(r=.26, p<.004)$ and 'unsociability' $(\mathrm{r}=.33, \mathrm{p}=.0002)$.

\subsubsection{Relations of reading-related skills and teachers' behavioral questionnaire at}

kindergarten and at fifth grade. As a first step, we aimed at examining the concurrent associations between children's performance in the BSEDS battery and teachers' behavioral reports at kindergarten, as well as the relationship between the word reading outcome and teachers' behavioral reports at fifth grade. For this purpose, we conducted correlation analyses between children's performance in the BSEDS battery and teachers' behavioral reports at kindergarten, and between the word reading outcome and teachers' behavioral reports at fifth grade. At the kindergarten level, the results indicated that the BSEDS global score was correlated with teachers' reports of 'inattention' $(r=-.43, p<.001)$, 'hyperactivity' $(r=-.24, p<.001)$, 'unsociability' $(\mathrm{r}=-.23, \mathrm{p}<.001)$ and 'conduct problems' $(\mathrm{r}=-.10, \mathrm{p}<.05)$.

In fifth grade, the results revealed that only 'inattention' reported by the teacher was concurrently related with word reading at fifth-grade $(\mathrm{r}=-.34, \mathrm{p}<.001)$. Neither 'hyperactivity', 'conduct problems or 'unsociability' were significantly correlated with the word reading composite score in the fifth grade ( $p>.05$ in all cases).

\subsubsection{Relations of emergent literacy skills, familial antecedents of reading} difficulties and teachers' behavioral questionnaire at kindergarten. We aimed to examine the pattern of concurrent relations between teachers' reports of behavioral problems, familial antecedents of reading difficulties and the overall performance in the BSEDS battery. For this purpose, $\mathrm{t}$ tests were conducted in order to analyze group differences in the BSEDS global score 
and teachers' behavioral reports according to parents' educational level and familial antecedents of reading difficulties. The results revealed significant group differences in BSEDS global scores and teachers' behavioral reports according to parents' educational level and familial antecedents of reading difficulties. Students that had parents with lower education levels presented lower BSEDS global scores $(\mathrm{t}=-7.11, \mathrm{p}<.001)$ and a higher proportion of 'inattention' symptoms reported by the teacher $(\mathrm{t}=2.98, \mathrm{p}=.003)$. Similarly, students whose parents had reported familial antecedents of reading difficulties presented lower BSEDS global scores $(t=3.16, p=$ $.002)$ and a higher frequency of 'inattention' reports from the teacher $(\mathrm{t}=-3.07, \mathrm{p}=.002)$. Teachers' reports of 'hyperactivity', ‘conduct problems' or 'unsociability' did not differ significantly according to parents' educational level or familial antecedents of reading difficulties ( $p>.05$ in all cases). Moreover, chi-square comparisons revealed that reports of antecedents of reading difficulties in the family came from parents who had significantly lower educational levels (chi-square $(1)=28.03, \mathrm{p}<.001)$.

Finally, we performed a series of regression analyses to examine the unique contribution of the behavioral and familial variables to the proportion of variance explained in the BSEDS global composite score at kindergarten. For this purpose, teachers' reports of behavioral problems were entered in the first set of analysis, and familial antecedents of reading difficulties and parents' educational level were progressively added to the statistical model. Only the variables predicting the BSEDS global score were retained in the final model. As seen in table 5, results from our first set of analysis (Step 1) indicated that the four teachers' factors accounted for $20 \%$ of the BSEDS overall performance in kindergarten $\left(\mathrm{r}^{2}=20 \%\right)$. When considering each of the teachers' factors, 'inattention', 'conduct problems' and 'unsociability' had a significant impact on BSEDS overall performance, whereas 'hyperactivity' had no significant effect. It is 
worth noting that the coefficient of 'conduct problems' is positive and significant $(\mathrm{p}=0.04)$ suggesting that absence of such "problems" has a negative effect on BSEDS when 'inattention" and 'unsociability' are taken into account. Due to the marginal values of statistical significance evidenced by these factors, teachers reports of 'hyperactivity', 'conduct problems' and 'unsociability' were eliminated from the model. Therefore, in the second step of analysis (Step 2), we entered in the regression the teachers' 'inattention' factor together with the measure of familial antecedents of reading difficulties. The results indicated that these two variables had a significant influence on the proportion of variance of the BSEDS global score $\left(\mathrm{r}^{2}=20 \%\right)$. In the

final set of analysis (Step 3), parents' educational level, teachers' reports of 'inattention' and familial antecedents of reading difficulties were simultaneously added to our model. Collectively, these three variables accounted for $25 \%$ of the unique variance of the BSEDS global score at kindergarten.

$<$ Insert Table 5 here >

\subsubsection{Relations of familial antecedents of reading difficulties with teachers'} behavioral questionnaire and word reading at fifth grade. In order to examine group differences in the word reading score and teachers' reports of behavioral problems at fifth grade according to familial antecedents of reading difficulties and parents' educational level, $\mathrm{t}$ test comparisons were performed. Results revealed that parental reports of familial antecedents of reading difficulties were related with lower word reading scores $(\mathrm{t}=3.33, \mathrm{p}=.001)$ and with a higher frequency of teachers' reports of 'inattention' $(\mathrm{t}=-2.75, \mathrm{p}=.007)$. Conversely, parents' education level was not related neither with the word reading outcome and teachers' reports of 
'inattention' at fifth grade, nor with the parental reports of familial antecedents of reading difficulties $(p>.05)$. Similarly, teachers' reports of 'hyperactivity', 'conduct problems' and 'unsociability' were not significantly related with parents' educational level and familial antecedents of reading difficulties ( $\mathrm{p}>.05$ in all cases).

\subsection{Longitudinal analyses}

\subsubsection{Relations of emergent literacy skills, familial antecedents of reading difficulties and teachers' behavioral questionnaire (kindergarten and fifth grade) with word reading at fifth grade. The longitudinal contribution of the variables included in the} present study to the prediction of the word reading outcome at fifth grade was assessed by means of regression analysis. The results of these analyses are presented in table 6 and depict the coefficient attributed to each study variable in the prediction of word reading at fifth grade and the proportion of variance uniquely accounted by each variable included in the statistical model. These results were obtained from different sets of regression analysis and only the variables significantly correlated with fifth grade word reading were included in these analyses. This eliminated all variables except teachers' reports of 'inattention' at fifth grade $(r=-.34, p=$ $.0002)$, parental reports of familial antecedents of reading difficulties $(r=-.26, p=.001)$, and three emergent literacy measures from the BSEDS battery at kindergarten, namely syllabic deletion $(\mathrm{r}=.30, \mathrm{p}=.0002)$, oral comprehension $(\mathrm{r}=.24, \mathrm{p}=.003)$ and letter reading $(\mathrm{r}=.31, \mathrm{p}$ $=.0001)$

The first set of regression analyses (Step1) examined the unique influence of familial antecedents of reading difficulties and teachers' reports of 'inattention' at fifth grade on the word reading outcome, without controlling for the effects of the literacy-related variables measured at kindergarten. The results indicated that these two variables uniquely accounted for $15 \%$ of the 
proportion of variance of the word reading outcome at fifth grade. In a second stage (Step 2), we entered the abovementioned BSEDS subtests into our analysis as possible predictors of word reading at fifth grade. The results indicated that the subtests of syllabic deletion, oral comprehension and letter reading made significant independent contributions to the prediction of fifth-grade word reading $\left(\mathrm{r}^{2}=.18\right)$.

Subsequently, familial antecedents of reading difficulties (Step 3) and teachers' reports of 'inattention' at fifth grade (Step 4) were progressively added to the model one at a time, while controlling for the effects of the three BSEDS subtests on word reading at fifth grade. This allowed us to assess the unique contribution of familial antecedents of reading difficulties and teachers' reports of 'inattention' at fifth grade in the proportion of variance of word reading. The inclusion of familial antecedents of reading acquisition in the statistical model contributed to increase the proportion of total variance explained by these four variables $\left(r^{2}=.20\right)$. Despite the reasonably low, although statistically significant, proportion of variance explained by familial antecedents of reading acquisition, the results of this model demonstrate the unique contribution of familial antecedents of reading difficulties in the word reading outcome at fifth grade, even after the emergent literacy variables were entered into the model. In contrast (Step 4), despite the unique contribution of fifth grade teachers' reports of 'inattention' in the proportion of variance explained in the word reading outcome $\left(\mathrm{r}^{2}=.25\right)$, its value has failed to reach significance once the emergent literacy skills measured at kindergarten were taken into account. This result suggests that the emergent literacy skills measured at kindergarten accounted for the association between teachers' reports of 'inattention' and word reading at fifth grade. Therefore, we conducted a correlation analysis to examine the association between teachers' reports of 'inattention' at fifth grade and the BSEDS subtests administered during kindergarten that 
significantly predicted the word reading outcome at fifth grade. Results evidenced that only the subtest of letter reading was significantly correlated with teachers' report of 'inattention' at fifth grade $(r=-.30, p=.001)$. This result suggests that the association between teachers' reported 'inattention' and word reading at fifth grade was mediated by the study's measure of letter reading skills.

The final set of regression analyses (Step 5) included the simultaneous entry of all the abovementioned variables as explanatory variables of the fifth grade word reading outcome. In these analyses, the measure of oral comprehension failed to approach statistical significance and was not included in the final model $(\mathrm{p}=.30)$. Results revealed that the variables of syllabic deletion, letter reading, familial antecedents of reading difficulties and teachers' reports of 'inattention' accounted for $26 \%$ of the proportion of variance of the word reading outcome at fifth grade. However, in this regression, both familial antecedents of reading difficulties and teachers' reports of 'inattention' only marginally contributed to the prediction of the word reading outcome in fifth grade $(\mathrm{p}=.08$ and $\mathrm{p}=.10$, respectively).

Overall, these results suggest that emergent literacy skills at kindergarten mediate to some extent the effect of familial antecedents of reading difficulties and teachers' reports of 'inattention' on the reading outcome at fifth grade.

\section{< Insert Table 6 here >}

Lastly, chi-square and t tests were used to compare children with reading difficulties and normal readers according with sociodemographic background and the variables significantly correlated with word reading at fifth grade. As seen in Table 7 and 8, the results of these analyses 
corroborated largely the findings from the regression analysis, with the exception of teachers' reports of 'inattention". The reading difficulties group presented lower performances on the subtests of syllabic deletion, oral comprehension and letter reading and there was a large effect of these variables in the differences observed between groups (Cohen, 1992). In addition, this group also presented a higher frequency of parental reports of familial antecedents of reading difficulties when compared with the normal readers group. However, there were no significant differences between these two groups concerning teachers' reports of 'inattention' $(p=.09)$.

< Insert Table 7 and 8 here >

\section{Discussion}

The purpose of the present study was to investigate the longitudinal associations between a host of early literacy-related and behavioral variables with word reading achievement in a sample of French students followed from kindergarten to the fifth grade. A second aim of the study was to extend previous findings concerning the association of familial antecedents of reading difficulties, teachers' reports of behavioral problems and emergent literacy skills at kindergarten with word reading achievement at the end of elementary school. Although previous studies in France have examined the role of cognitive, familial and behavioral factors in the subsequent reading achievement of French children (Billard et al., 2008, 2009; Fluss et al., 2008; Watier et al., 2006), few longitudinal studies have focused on the developmental precursors of mid-term reading achievement in a non-diagnosed community sample. The longitudinal analysis reported here is one of the first works comprising a time period as long as 6 years of formal school instruction. 
The cross sectional analyses performed at kindergarten between teachers' reports of behavioral problems and the overall performance in the BSEDS battery revealed that 'hyperactivity' 'inattention', 'conduct problems' and unsociability' were significantly associated with the BSEDS global score, in accordance with the often-cited link between externalizing behavior problems and reading achievement (Hinshaw, 1992, for a review). However, the results from the regression analysis revealed that teachers' reports of 'inattention', when compared with the remaining reports of classroom behavior, were most consistently associated with the global performance in the BSEDS battery. These results corroborate previous findings concerning the significant association between attention problems and emergent literacy skills in preschool children (Giannopulu et al., 2008; Lonigan et al., 1999). Interestingly, the results of the present study indicated that children rated by their teachers as 'inattentive' and unsociable presented lower scores in the BSEDS battery, when compared with children whose teachers reported 'inattention' and unsociability symptoms concurrently with 'conduct problems'. This particular finding has important educational implications. As pointed out by Barriga and colleagues (2002), children who do not exhibit symptoms that cause some disturbance in the classroom can be hard to detect by their teachers and to be referred for further assessment and remediation. In what concerns the current study, a reasonable explanation for these findings is that the children who manifested both inattentive and disruptive behaviors during the preschool period, had already been referred to educational supervision due to their disruptive problems and, thus, might have benefited from adequate intervention strategies compared with children who exhibited inattention and unsociability symptoms exclusively.

Furthermore, the pattern of concurrent associations at fifth grade between teachers' reports of behavioral problems and the word reading outcome revealed that only 'inattention' 
was significantly correlated with word reading in the same school period, and is in line with the results obtained in the kindergarten period. This result seems to reflect the cross-sectional association found in numerous studies between inattention and word reading achievement in elementary school children (Billard et al., 2009; Dally, 2006; Giannopulu et al., 2008; McGee et al., 2002; Rabiner \& Coie, 2000; Roy \& Rutter, 2006). Reading difficulties were shown to be more strongly associated with the inattentive subtype of ADHD (Giannopulu et al., 2008; Hinshaw, 1992; Lundervold, Heimann \& Manger, 2008; Willcutt \& Pennington, 2000a) and the association between conduct problems and reading difficulties was mediated by co-morbid ADHD (Carroll et al., 2004; Willcutt \& Pennington, 2000b).

In addition, the findings of the cross sectional analyses performed in the kindergarten period revealed that teachers' reports of 'inattention', together with parents' educational level and familial antecedents of reading difficulties independently accounted for $25 \%$ of the variance in the BSEDS global score, even after controlling for all the other behavioral and background variables. Furthermore, the results at the kindergarten period revealed significant group differences in the BSEDS global performance and teachers' reports of 'inattention' when parents' education level was taken into account. This result corroborates the findings from several studies indicating that parents' level of education influences considerably the development of early reading skills (Billard et al., 2008; Dellatolas et al., 2006; Hecht et al., 2000) and that attention skills are highly associated with parental education (Billard et al., 2010; Dellatolas et al., 2006; Pennington et al., 2009, for a review). In the same vein, children whose parents reported familial antecedents of reading difficulties presented lower $B S E D S$ ' global scores and a higher frequency of 'inattention' symptoms reported by the teacher. These results provide support to the contention that both reading difficulties and ADHD are highly familial (Pennington et al., 2009, 
for a review). Several studies have reported that children at family risk of dyslexia, where at least one member of the family was reported to be dyslexic, presented lower scores in key early reading-related skills during kindergarten and were at increased risk of developing literacy problems (Snowling et al., 2003; Puolakanaho et al., 2007). The results from the present study regarding the shared association of familial antecedents of reading difficulties with both emergent literacy skills and teachers' inattention reports provide an extension of the above-cited findings by presenting evidence that children at familial risk of developing reading difficulties might also be at increased risk for attention problems. Moreover, these results replicate the findings obtained by Doyen and colleagues (2004) from their analyses of the relationship among familial antecedents of reading difficulties, early literacy skills and teachers' reports of inattention symptoms during kindergarten. In this sense, children raised in families characterized by a history of difficulties in learning to read are not only at risk of developing reading difficulties, but might also be especially vulnerable to the development of attention problems. Importantly, the results of the current study highlight the significant association between parental reports of familial antecedents of reading difficulties and parents' educational level at kindergarten. Families where only one of the parents had a high school diploma more frequently reported the presence of difficulties in learning to read in at least one member of the family (i.e. a sibling and/or the parents). These findings invite the hypothesis that the co-occurrence of early reading difficulties and attention problems in children with a familial history of reading difficulties is particularly associated with environmental factors, such as parental education. Children from families characterized by low parental education levels and a family history of reading difficulties might be at increased risk of developing co-morbid reading difficulties and attention problems, due to the well established interference of inattentive behavior in reading 
acquisition (Dally, 2006), especially in disadvantaged environments (Velting \& Whitehurst, 1997).

The results from the longitudinal analyses indicated that both familial antecedents of reading difficulties and teachers' 'inattention' reports at fifth grade made significant contributions to the prediction of fifth grade word reading. However, neither of these variables explained a significant proportion of variance in word reading at fifth grade beyond that accounted by the measures of syllabic deletion and letter reading at kindergarten. These two measures embody often-cited skills considered of major importance in reading development, namely phonological awareness and letter knowledge. The role of these early reading-related skills on the acquisition of word identification skills is well established, in accordance with an extensive body of literature (Castles \& Coltheart, 2004; Hecht et al., 2000; Hulme et al., 2005; Sprenger-Charolles et al., 2003; Whitehurst \& Lonigan, 1998). Most importantly, the results from the longitudinal analyses confirmed that parents' reports of familial antecedents of reading difficulties were longitudinally associated both with lower word reading scores and teachers' 'inattention' reports at fifth grade. In the same line, group comparisons between normal readers and children who presented lower performances on the word reading outcome at fifth grade lent support to these results by revealing that these groups were reliably different from one another on measures of syllabic deletion, letter reading, familial antecedents of reading difficulties and teachers' reports of 'inattention' problems. Taken together, these results confirm the pertinence of including these measures in screening procedures aimed to identify children at risk of developing reading difficulties. Puolakanaho and colleagues (2007) have demonstrated that a rough screening procedure including familial risk status and measures of phonological awareness, letter knowledge and rapid naming provided a reliable method for estimating a 
child's individual risk for developing RD from the age of 3.5 years. The results of the present study extend these findings by demonstrating that preschoolers with a family history of reading difficulties might also be at increased risk of manifesting co-morbid attention problems at the end of elementary school together with reading difficulties. This assumption is contingent with the results obtained by Hynd et al. (1991) who indicated that children with attention-deficit disorder without hyperactivity (ADD/WO) were more likely to exhibit a family history of reading difficulties. Unique to the present study is the finding of the longitudinal association between reading difficulties and attention problems in children with a family history of reading difficulties in a non-diagnosed community sample followed from preschool to late elementary school, some of whom would have been expected to develop reading problems. These results concur with research evidences from family studies regarding the shared familiality of RD and ADHD (Friedman et al., 2003) and suggest that family factors play a role in the co-occurrence of these two disorders. Furthermore, our results align well with twin studies that recently demonstrated that the association between $\mathrm{RD}$ and inattention symptoms is in place during kindergarten (Ebejer et al, 2010; Willcutt et al., 2007) and is largely driven by genetic and environmental factors (Paloyelis et al., 2010). Taken together, the findings here presented underline the importance of considering the contribution of family-specific factors as antecedent variables in the co-occurrence of reading difficulties and inattention behavioral problems from kindergarten onwards.

Finally, teachers' 'inattention' reports at kindergarten and at fifth grade were not predictive of the word reading outcome at fifth grade over and beyond the study's measures of syllabic deletion and letter knowledge. This result is concurrent with the findings of Castellanos and Tannock (2002) who concluded that teachers' reported inattention is not necessarily specific, 
as the relation between it and specific attention tests is not necessarily strong or even significant (Castellanos \& Tannock, 2002). Likewise, it is possible that teachers tend to systematically report inattention in pupils with reading problems, since both reading difficulties and the inattentive subtype of ADHD often manifest themselves in poor reading performance (Aaron et al., 2002). Hence, the association between teachers' judgments of classroom inattention and children's cognitive and academic performance puts forward the assumption that teachers' reported inattention might rely on the observation of low cognitive and academic performances (Giannopulu et al, 2008).

In summary, the present study has confirmed the crucial role that phonological awareness and letter knowledge play as developmental precursors of word reading skills in a sample of French students followed from kindergarten to fifth grade. In addition, our results suggest that familial antecedents of reading difficulties constitute an important risk indicator of those children who probably will develop reading difficulties. Most importantly, the current study presented evidence that children whose parents reported familial antecedents of reading difficulties were more likely to have lower performances on reading-related tasks, and to be rated by their teachers as inattentive, both at kindergarten and at the end of elementary school.

There are a number of limitations to this study that should be mentioned. The community sample used in the present study was drawn from a rural and suburban total population enrolled in general education classrooms and therefore caution is warranted in the interpretation of our results with respect to generalization of the findings to other populations. In addition, logistic constraints limited the follow-up of a larger sample of children from preschool through fifthgrade, which explains the high attrition rate verified between the two school years. Consequently, despite the important size of the kindergarten sample, the size of the fifth grade 
sample constrained the power of the data analysis performed in the present study and hindered the use of alternative statistical models, such as structural equation modeling. Similarly, the fifth grade sample size limited the analysis of the group comparisons between normal readers and the reading difficulties group. The significantly reduced proportion of students at-risk of experiencing reading difficulties in the fifth grade sample restricted the examination of the extent to which the prediction patterns would hold up for this particular group. Second, the classification of behavioral problems as 'hyperactivity', 'inattention', 'conduct problems' and 'unsociability' relied on teachers' responses to four questions by category and thus do not reflect true diagnostic categories. Additionally, the study of the association between behavioral problems such as inattention and reading difficulties implies the consideration of several external correlates of both disorders, namely: IQ, socio cultural background, family environment, among others. In the present study, only parents' level of education was considered. Moreover, the presence of missing data coupled with our reliance in the treatment of complete cases may have obscured significant relations between variables, namely the association between inattentive behavior at kindergarten with subsequent inattentive behavior and word reading achievement at fifth grade. Finally, our results do not indicate the specific nature of the familial history of reading difficulties and were based on parent's responses to two questions. Although these caveats restrained the power and extension of the data analysis conducted in the present study, these limitations do not exclude the validity and pertinence of the findings regarding the shared influence of familial antecedents of reading difficulties on both reading and inattentive behavior.

\section{Implications and future research directions}

The educational implication of the findings here presented is noteworthy. The inclusion of information about familial antecedents of reading difficulties in screening procedures during 
preschool improves the early identification of children that might develop reading difficulties at the end of elementary school. Importantly, the results indicated that children characterized by a familial history of reading difficulties might represent a vulnerable group in risk of manifesting concurrent attention problems from preschool to fifth grade. Moreover, emergent literacy skills at kindergarten mediated to some extent the effect of familial antecedents of reading difficulties and teachers' reports of 'inattention' on the reading outcome at fifth grade. Taken all together, these findings emphasize the importance of considering familial antecedents of reading difficulties as an antecedent variable in the co-occurrence of reading difficulties and attention problems.

Further studies are needed that focus in more detail on the mechanisms by which familial antecedents of reading difficulties operate in learning difficulties in general and in reading development specifically. These studies should include additional measures of parental testing aimed at confirming and uncovering the specific nature of familial reading difficulties, as well as attention problems. This could allow the improvement of our understanding of which domains of familial antecedents of reading difficulties are related specifically with children's reading difficulties and attention problems. 


\section{Acknowledgements}

The present research was supported in part by Fédération des Oeuvres Laïques of the Urban Community of Creusot Montceau-les-Mines, the French Ministry of Health, France Foundation (Fondation de France), INSERM (Institut National de la Santé et de la Recherche Médicale) and MGEN (Mutuelle Générale de l'Éducation Nationale - Projet Maternelle). We are very thankful to the members of the research team, the school doctors and nurses of the National Department of Education, and the pediatricians, teachers and children of the community of Creusot Montceau-les-Mines for their participation in the study. 


\section{References}

Aaron, P. G., Joshi, R. M., Palmer, H., Smith, N., \& Kirby, E. (2002). Separating genuine cases of reading disability from reading deficits caused by predominantly inattentive ADHD behavior. Journal of Learning Disabilities, 35(5), 425.

doi:10.1177/00222194020350050301

Al Otaiba, S., \& Fuchs, D. (2006). Who are the young children for whom best practices in reading are ineffective? : An experimental and longitudinal study. Journal of Learning Disabilities, 39(5), doi:414-431. 10.1177/00222194060390050401

Angold, A., Costello, E. J., \& Erkanli. A. (1999). Comorbidity. Journal of Child Psychology and Psychiatry, 40(1), 57-87. doi:10.1111/1469-7610.00424

Barriga, A. Q., Doran, J. W., Newell, S. R., Morrison, E. M., Barbetti, V., \& Robbins, B. (2002). Relationships between problem behaviors and academic achievement in adolescents: The unique role of attention problems. Journal of Emotional and Behavioral Disorders, 10(4), 233-240. doi:10.1177/10634266020100040501

Billard, C. C., Fluss, J. J., Ducot, B. B., Warszawski, J. J., Ecalle, J. J., Magnan, A. A., \& ... Ziegler, J. J. (2008). Étude des facteurs liés aux difficultés d'apprentissage de la lecture. À partir d'un échantillon de 1062 enfants de seconde année d'école élémentaire. [Study of causal factors of reading impairment in a sample of 10627 to 8-years-old children]. Archives de Pédiatrie, 15(6), 1058-1067. doi:10.1016/j.arcped.2008.02.020

Billard, C., Bricout, L., Ducot, B., Richard, G., Ziegler, J. \& Fluss, J. (2010). Évolution des compétences en lecture, compréhension et orthographe en environnement socioéconomique défavorisé et impact des facteurs cognitifs et comportementaux sur le devenir à deux ans [Reading, spelling and comprehension level in low socioeconomic 
backgrounds: Outcome and predictive factors]. Revue d'Épidémiologie et de Santé Publique, 58, 101-110. doi:10.1016/j.respe.2009.11.002

Billard, C., Fluss, J., Ducot, B., Bricout, L., Richard, G., Ecalle, J., ... Ziegler, J. J. (2009).Troubles d'acquisition de la lecture en cours élémentaire: facteurs cognitifs, sociaux et comportementaux dans un échantillon de 1062 enfants. [Deficits in reading acquisition in primary school: Cognitive, social and behavioral factors studied in a sample of 1062 children]. Revue d'Épidémiologie et de Santé Publique, 57, 191-203. doi:10.1016/j.respe.2009.02.205

Bracken, S. S., \& Fischel, J. E. (2007). Relationships between social skills, behavioral problems, and school readiness for head start children. National Head Start Association, 10(2), 109126.

Bradley, R. H., \& Corwyn, R. F. (2002). Socioeconomic status and child development. Annual Review of Psychology, 53(1), 371-399. doi:10.1146/annurev.psych.53.100901.135233

Bub, K. L., McCartney, K., \& Willett, J. B. (2007). Behavior problem trajectories and first-grade cognitive ability and achievement skills: A latent growth curve analysis. Journal of Educational Psychology, 99(3), 653-670. doi:10.1037/0022-0663.99.3.653

Burchinal, M. R., Peisner-Feinberg, E., Pianta, R., \& Howes, C. (2002). Development of academic skills from preschool through second grade: Family and classroom predictors of developmental trajectories. Journal of School Psychology, 40(5), 415-436. doi:10.1016/S0022-4405(02)00107-3

Callu, D. D., Giannopulu, I. I., Escolano, S. S., Cusin, F. F., Jacquier-Roux, M. M., \& Dellatolas, G. G. (2005). Smooth pursuit eye movements are associated with phonological awareness 
in preschool children. Brain and Cognition, 58(2), 217-225.

doi:10.1016/j.bandc.2004.11.008

Callu, D. D., Jacquier-Roux, M. M., Cusin, F. F., Giannopulu, I. I., \& Dellatolas, G. G. (2003). Pertinence du repérage par les parents des retards de langage chez l'enfant entre quatre et six ans. [Pertinence of parental screening for delays of language in children aged four to six years]. Archives de Pédiatrie, 10(12), 1061. doi:10.1016/j.arcped.2003.09.034

Campbell, F. A., Pungello, E. P., Miller-Johnson, S., Burchinal, M., \& Ramey, C. T. (2001). The development of cognitive and academic abilities: Growth curves from an early childhood educational experiment. Developmental Psychology, 37(2), 231-242. doi:10.1037/00121649.37.2.231

Carroll, J. M., Maughan, B., Goodman, R., \& Meltzer, H. (2004). Literacy difficulties and psychiatric disorders: Evidence for comorbidity. Journal of Child Psychology and Psychiatry, 46(5), 524-532. doi:10.1111/j.1469-7610.2004.00366.x

Castellanos, F., \& Tannock, R. (2002). Neuroscience of attention-deficit/hyperactivity disorder: The search for endophenotypes. Nature Reviews Neuroscience, 3(8), 617-628. doi:10.1038/nrn896

Castles, A., \& Coltheart, M. (2004). Is there a causal link from phonological awareness to success in learning to read? Cognition, 91(1), 77-111. doi:10.1016/S00100277(03)00164-1

Cohen, J. (1992). A power primer. Psychological Bulletin. 112(1), 155-159. doi: 10.1037/00332909.112.1.155 
Cunningham, A. E., \& Stanovich, K. E. (1997). Early reading acquisition and its relation to reading experience and ability 10 years later. Developmental Psychology, 33(6), 934-945. doi:10.1037/0012-1649.33.6.934

Dally, K. (2006). The influence of phonological processing and inattentive behavior on reading acquisition. Journal of Educational Psychology, 98(2), 420-437. doi:10.1037/00220663.98.2.420

de Santos Loureiro, C., Braga, L., do Nascimento Souza, L., Filho, G., Queiroz, E., \& Dellatolas, G. (2004). Degree of illiteracy and phonological and metaphonological skills in unschooled adults. Brain and Language, 89(3), 499-502. doi:10.1016/j.bandl.2003.12.008

Dellatolas, G. G., Watier, L. L., Giannopulu, I. I., \& Chevrie-Muller, C. C. (2006). Comportement perturbateur, difficultés d'attention et apprentissages entre 3,5 ans et 8 ans: une étude longitudinale en milieu scolaire. [Behavior difficulties, attention difficulties and learning problems in children aged from 3,5 to 8 years: a longitudinal school study]. Archives de Pédiatrie, 14(3), 227-233. doi:10.1016/j.arcped.2006.10.022

Dellatolas, G., Braga, L., Souza, L., Filho, G., Queiroz, E., \& Deloche, G. (2003). Cognitive consequences of early phase of literacy. Journal of the International Neuropsychological Society, 9(5), 771-782. doi:10.1017/S1355617703950107

Doctoroff, G. L., Greer, J. A., \& Arnold, D. H. (2006). The relationship between social behavior and emergent literacy among preschool boys and girls. Journal Of Applied Developmental Psychology, 27(1), 1-13.

Doyen, A. L., Giannopulu, I. I., Escolano, S. S., Cusin, F. F., Jacquier-Roux, M. M., \& Dellatolas, G. G. (2004). Antécédents parentaux de difficultés langagières et évaluation du langage chez l'enfant entre cinq et six ans. [Parental antecedents of language problems 
and langage evaluation in five and six-year-old children]. Archives de Pédiatrie, 11(10), 1249-1250. doi:10.1016/j.arcped.2004.06.037

Duncan, G. J., Dowsett, C. J., Claessens, A., Magnuson, K., Huston, A. C., Klebanov, P., \& ... Japel, C. (2007). School readiness and later achievement. Developmental Psychology, 43(6), 1428-1446. doi:10.1037/0012-1649.43.6.1428

Ebejer, J. L., Coventry, W. L., Byrne, B., Willcutt, E. G., Olson, R. K., Corley, R., \& Samuelsson, S. (2010). Genetic and environmental influences on inattention, hyperactivity-impulsivity, and reading: Kindergarten to grade 2. Scientific Studies of Reading, 14(4), 293-316. doi:10.1080/10888430903150642

Entwisle, D. R., \& Alexander, K. L. (1998). Facilitating the transition to first grade: The nature of transition and research on factors affecting it. The Elementary School Journal, 98(4), 351-364. doi:10.1086/461901

Fluss, J. J., Ziegler, J. J., Ecalle, J. J., Magnan, A. A., Warszawski, J. J., Ducot, B. B., \& ... Billard, C. C. (2008). Prévalence des troubles d'apprentissages du langage écrit en début de scolarité: l'impact du milieu socioéconomique dans 3 zones d'éducations distinctes. [Prevalence of reading disabilities in early elementary school: Impact of socioeconomic environment on reading development in 3 different educational zones]. Archives de Pédiatrie, 15(6), 1049-1057. doi:10.1016/j.arcped.2008.02.012

Friedman, M., Chhabildas, N., Budhiraja, N., Willcutt, E., \& Pennington, B. (2003). Etiology of the comorbidity between RD and ADHD: Exploration of the non-random mating hypothesis. American Journal of Human Genetics, 120B, 109-115. doi:

10.1002/ajmg.b.20029 
Giannopulu, I. I., Cusin, F. F., Escolano, S. S., \& Dellatolas, G. G. (2007). Cognitive associations of bimanual haptico-visual recognition in preschoolers. Child Neuropsychology, 14(3), 227-236. doi:10.1080/09297040701314881

Giannopulu, I. I., Escolano, S. S., Cusin, F. F., Citeau, H. H., \& Dellatolas, G. G. (2008). Teachers' reporting of behavioural problems and cognitive-academic performances in children aged 5-7 years. British Journal of Educational Psychology, 78(1), 127-147. doi:10.1348/000709907X204372

Hecht, S. A., Burgess, S. R., Torgesen, J. K., Wagner, R. K., \& Rashotte, C. A. (2000). Explaining social class differences in growth of reading skills from beginning kindergarten through fourth-grade: The role of phonological awareness, rate of access, and print knowledge. Reading and Writing, 12(1-2), 99-127. doi:10.1023/A:1008033824385

Heckman, J. J. (2006). Skill formation and the economics of investing in disadvantaged children. Science, 312(5782), 1900-1902. doi:10.1126/science.1128898

Hinshaw, S. P. (1992). Externalizing behavior problems and academic underachievement in childhood and adolescence: Causal relationships and underlying mechanisms. Psychological Bulletin, 111(1), 127-155. doi:10.1037/0033-2909.111.1.127

Hulme, C., Snowling, M., Caravolas, M., \& Carroll, J. (2005). Phonological skills are (probably) one cause of success in learning to read: A comment on Castles and Coltheart. Scientific Studies of Reading, 9(4), 351-365.doi:10.1207/s1532799xssr0904_2

Hynd, G. W., Lorys, A. R., Semrud-Clikeman, M., \& Nieves, N. (1991). Attention deficit disorder without hyperactivity: A distinct behavioral and neurocognitive syndrome. Journal of Child Neurology, 6(Suppl), S37-S43. doi:10.1177/0883073891006001051 
Institut National de la Santé et de la Recherche Médicale (2007). Dyslexie, dysorthographie, dyscalculie: Bilan des données scientifiques. [Dyslexia, dysorthography and dyscalculia: Review of scientific data]. Paris, France: Les Éditions Inserm.

Jacquier-Roux, M., Valdois, S., \& Zorman, M. (2002). Un outil de dépistage des dyslexies développementales (ODEDYS). [A screening instrument for developmental dyslexia]. Retrieved November 12, 2008, from http://www.grenoble.iufm.fr/recherch/cognisciences/index.html

Jordan, G. E., Snow, C. E., \& Porche, M. V. (2000). Project EASE: The effect of a family literacy project on kindergarten students' early literacy skills. Reading Research Quarterly, 35(4), 524-546. doi:10.1598/RRQ.35.4.5

Lefavrais, P. (2006). Alouette R: test d'analyse de la vitesse de lecture à partir d'un texte. [Alouette R: analysis test of text-reading speed]. Paris, France: Les Editions du Centre de Psychologie Appliquée.

Lonigan, C. J., Bloomfield, B. G., Anthony, J. L., Bacon, K. D., Phillips, B. M., \& Samwel, C. S. (1999). Relations among emergent literacy skills, behavior problems, and social competence in preschool children from low- and middle-income backgrounds. Topics in Early Childhood Special Education, 19(1), 40-53. doi:10.1177/027112149901900104

Lonigan, C. J., Burgess, S. R., \& Anthony, J. L. (2000). Development of emergent literacy and early reading skills in preschool children: Evidence from a latent-variable longitudinal study. Developmental Psychology, 36(5), 596-613. doi:10.1037/0012-1649.36.5.596

Lundervold, A. J., Heimann, M. M., \& Manger, T. T. (2008). Behaviour-emotional characteristics of primary-school children rated as having language problems. British Journal of Educational Psychology, 78(4), 567-580. doi:10.1348/000709908X320480 
Maughan, B. B., Messer, J. J., Collishaw, S. S., Pickles, A. A., Snowling, M. M., Yule, W. W., \& Rutter, M. M. (2009). Persistence of literacy problems: Spelling in adolescence and at mid-life. Journal of Child Psychology and Psychiatry, 50(8), 893-901. doi:10.1111/j.1469-7610.2009.02079.x

McGee, R., Prior, M., Williams, S., Smart, D., \& Sanson, A. (2002). The long-term significance of teacher-rated hyperactivity and reading ability in childhood: Findings from two longitudinal studies. Journal of Child Psychology and Psychiatry, 43(8), 1004-1016. doi:10.1111/1469-7610.00228

Merrell, C. C., \& Tymms, P. B. (2001). Inattention, hyperactivity and impulsiveness: Their impact on academic achievement and progress. British Journal of Educational Psychology, 71(1), 43-56. doi:10.1348/000709901158389

Muter, V., Hulme, C., Snowling, M. J., \& Stevenson, J. (2004). Phonemes, rimes, vocabulary, and grammatical skills as foundations of early reading development: Evidence from a longitudinal study. Developmental Psychology, 40(5), 665-681. doi:10.1037/00121649.40 .5 .665

Paloyelis, Y., Rijsdijk, F., Wood, A. C., Asherson, P., \& Kuntsi, J. (2010). The Genetic Association Between ADHD Symptoms and Reading Difficulties: The Role of Inattentiveness and IQ. Journal Of Abnormal Child Psychology, 38(8), 1083-1095. doi:10.1007/s10802-010-9429-7

Pennington, B. F., McGrath, L. M., Rosenberg, J., Barnard, H., Willcutt, E. G., Friend, A., \& ... Smith, S. D. (2009). Gene X Environment interactions in reading disability and attentiondeficit/hyperactivity disorder. Developmental Psychology, 45(1), 77-89.

doi: $10.1037 / \mathrm{a} 0014549$ 
Pingault, J. B., Tremblay, R.E., Vitaro, F., Carbonneau, R., Genolini, C., Falissard, B., Côté, S. M. (2011) Childhood trajectories of inattention and hyperactivity and prediction of educational attainment in early adulthood: A 16-year longitudinal population-based study. The American Journal of Psychiatry. doi: 10.1176/appi.ajp.2011.10121732

Puolakanaho, A., Ahonen, T., Aro, M., Eklund, K., Leppänen, P. T., Poikkeus, A., \& ... Lyytinen, H. (2007). Very early phonological and language skills: Estimating individual risk of reading disability. Journal of Child Psychology and Psychiatry, 48(9), 923-931. doi:10.1111/j.1469-7610.2007.01763.x

Rabiner, D., Coie, J. D., \& The Conduct Problems Prevention Research Group. (2000). Early attention problems and children's reading achievement: A longitudinal investigation. Journal of the American Academy of Child \& Adolescent Psychiatry, 39(7), 859-867. doi:10.1097/00004583-200007000-00014

Rapport, M. D., Scanlan, S. W., \& Denney, C. B. (1999). Attention-deficit/hyperactivity disorder and scholastic achievement: A model of dual developmental pathways. Journal of Child Psychology and Psychiatry, 40(8), 1169-1183. doi:10.1111/1469-7610.00534

Roy, P., \& Rutter, M. (2006). Institutional care: Associations between inattention and early reading performance. Journal of Child Psychology and Psychiatry, 47(5), 480-487. doi:10.1111/j.1469-7610.2005.01526.x

Sénéchal, M., \& LeFevre, J. (2002). Parental involvement in the development of children's reading skill: A five-year longitudinal study. Child Development, 73(2), 445-460. doi:10.1111/1467-8624.00417 
Shaywitz, S. E., Fletcher, J. M. Holahan, J. M., Schneider, A. E., Marchione, K. E., Stuebing, K. K., \& ... Shaywitz, B.A. (1999). Persistence of dyslexia: The Connecticut longitudinal study at adolescence. Pediatrics, 104(6), 1351-1359. doi:10.1542/peds.104.6.1351

Shaywitz, S. E., Shaywitz, B. A., Fletcher, J. M., \& Escobar, M. D. (1990). Prevalence of Reading Disability in Boys and Girls. JAMA: Journal Of The American Medical Association, 264(8), 998.

Snowling, M. J., Gallagher, A., \& Frith, U. (2003). Family risk of dyslexia is continuous: Individual differences in the precursors of reading skill. Child Development, 74(2), 358373. doi:10.1111/1467-8624.7402003

Spira, E., Bracken, S., \& Fischel, J. (2005). Predicting improvement after first-grade reading difficulties: The effects of oral language, emergent literacy, and behavior skills. Developmental psychology, 41(1), 225-234. doi: 10.1037/0012-1649.41.1.225

Spira, E., \& Fischel, J. E. (2005). The impact of preschool inattention, hyperactivity, and impulsivity on social and academic development: a review. Journal of Child Psychology \& Psychiatry, 46(7), 755-773. doi:10.1111/j.1469-7610.2005.01466.x

Sprenger-Charolles, L. L., Colé, P. P., Béchennec, D. D., \& Kipffer-Piquard, A. A. (2005). French normative data on reading and related skills from EVALEC, a new computerized battery of tests (end Grade 1, Grade 2, Grade 3, and Grade 4). European Review of Applied Psychology/Revue Européenne de Psychologie Appliquée, 55(3), 157-186. doi:10.1016/j.erap.2004.11.002

Sprenger-Charolles, L., Siegel, L. S., Béchennec, D., \& Serniclaes, W. (2003). Development of phonological and orthographic processing in reading aloud, in silent reading, and in 
spelling: A four-year longitudinal study. Journal of Experimental Child Psychology, 84(3), 194-217. doi:10.1016/S0022-0965(03)00024-9

Stanovich, K. E. (1986). Matthew effects in reading: Some consequences of individual differences in the acquisition of literacy. Reading Research Quarterly, 21(4), 360-406. doi:10.1598/RRQ.21.4.1

Storch, S. A., \& Whitehurst, G. J. (2002). Oral language and code-related precursors to reading: Evidence from a longitudinal structural model. Developmental Psychology, 38(6), 934947. doi:10.1037/0012-1649.38.6.934

Torgesen, J. K., Wagner, R. K., Rashotte, C. A., Burgess, S., \& Hecht, S. (1997). Contributions of phonological awareness and rapid automatic naming ability to the growth of wordreading skills in second- to fifth-grade children. Scientific Studies of Reading, 1(2), 161185. doi:10.1207/s1532799xssr0102_4

Trzesniewski. K., Moffit, T., Caspi, A., Taylor, A., \& Maughan, B. (2006). Revisiting the association between reading achievement and antisocial behavior: New evidence of an environmental explanation from a twin study. Child development, 77(1), 72-88. doi: 10.1111/j.1467-8624.2006.00857.x

Vellutino, F. R., Fletcher, J. M., Snowling, M. J., \& Scanlon, D. M. (2004). Specific reading disability (dyslexia): what have we learned in the past four decades? Journal of Child Psychology and Psychiatry, 45(1), 2-40. doi:10.1046/j.0021-9630.2003.00305.x

Vaughn, S., Zaragoza, N., Hogan, A., \& Walker, J. (1993). A four-year longitudinal investigation of the social skills and behavior problems of students with learning disabilities. Journal of Learning Disabilities, 26(6), 404-412. doi:10.1177/002221949302600606 
Velting, O. N., \& Whitehurst, G. J. (1997). Inattention-hyperactivity and reading achievement in children from low-income families: A longitudinal model. Journal of Abnormal Child Psychology, 25(4), 321-331. doi:10.1023/A:1025716520345

Wagner, R. K., \& Torgesen, J. K. (1987). The nature of phonological processing and its causal role in the acquisition of reading skills. Psychological Bulletin, 101(2), 192-212. doi:10.1037/0033-2909.101.2.192

Wagner, R. K., Torgesen, J. K., Rashotte, C. A., Hecht, S. A., Barker, T. A., Burgess, S. R., \& ... Garon, T. (1997). Changing relations between phonological processing abilities and word-level reading as children develop from beginning to skilled readers: A 5-year longitudinal study. Developmental Psychology, 33(3), 468-479. doi:10.1037/00121649.33.3.468

Watier, L., Dellatolas, G. \& Chevrie-Muller, C. (2006). Difficultés de langage et de Comportement à 3,5 ans et retard de lecture au cours élémentaire. [Language and behavioral difficulties at age 3 and half and reading delay in grade 2]. Revue Épidémiologique de Santé Publique, 54, 327-334. doi : RESP-09-2006-54-4-0398-7620$101019-200605450$

Whitehurst, G. J., \& Lonigan, C. J. (1998). Child development and emergent literacy. Child Development, 69(3), 848-872. doi:10.2307/1132208

Willcutt, E. G., \& Pennington, B. F. (2000a). Comorbidity of reading disability and attentiondeficit/hyperactivity disorder: Differences by gender and subtype. Journal of Learning Disabilities, 33(2), 179-191. doi:10.1177/002221940003300206 
Willcutt, E. G., \& Pennington, B. F. (2000b). Psychiatric comorbidity in children and adolescents with reading disability. Journal of Child Psychology and Psychiatry, 41(8), 1039-1048. doi:10.1111/1469-7610.00691

Willcutt, E. G., Betjemann, R. S., Wadsworth, S. J., Samuelsson, S., Corley, R., Defries, J. C., \& ... Olson, R. K. (2007). Preschool twin study of the relation between attentiondeficit/hyperactivity disorder and prereading skills. Reading and Writing, 20(1-2), 103125. doi:10.1007/s11145-006-9020-3

Zorman, M., \& Jacquier-Roux, M. (2001). BSEDS 5-6: Bilan de Santé Évaluation du Développement pour la Scolarité 5 à 6 ans [Health Examination: Developmental assessment for school-aged children aged 5-6 years]. Retrieved November 20, 2008, from http://www.cognisciences.com/article.php3?id_article=36 
Table 1

Descriptive statistics of the study variables at kindergarten

\begin{tabular}{|c|c|c|c|c|c|c|}
\hline Kindergarten variables & $\mathrm{N}$ & $\%$ & $\mathrm{M}$ & SD & Min & Max \\
\hline Sociodemographic background & 812 & & & & & \\
\hline Sex (boys) & & 52 & & & & \\
\hline Age (years) & & & 5.84 & .34 & 5.07 & 7.19 \\
\hline \multicolumn{7}{|l|}{ Parents educational level } \\
\hline At least one parent has high school diploma & 382 & 47 & & & & \\
\hline \multicolumn{7}{|l|}{ Familial antecedents of reading difficulties } \\
\hline (cases reported) & 171 & 21 & & & & \\
\hline \multicolumn{7}{|l|}{ BSEDS } \\
\hline Global composite score & 677 & & .71 & .14 & .24 & .99 \\
\hline Phonological awareness composite score & 789 & & 15.70 & 5.85 & 0 & 23 \\
\hline Rhymes & 796 & & 5.37 & 2.41 & 0 & 8 \\
\hline Syllabic counting & 794 & & 4.38 & 1.17 & 0 & 5 \\
\hline Syllabic deletion & 789 & & 5.89 & 3.63 & 0 & 10 \\
\hline Vocabulary & 753 & & 20.18 & 4.29 & 1 & 30 \\
\hline Pseudoword Repetition & 796 & & 12.55 & 3.13 & 1 & 16 \\
\hline Oral Comprehension & 798 & & 7.53 & 1.74 & 1 & 10 \\
\hline Letter reading & 786 & & 5.82 & 3.38 & 0 & 12 \\
\hline Sentence repetition & 766 & & 13.78 & 2.89 & 0 & 16 \\
\hline Figure reproduction & 781 & & 4.24 & 1.88 & 0 & 6 \\
\hline Teachers' Questionnaire & 590 & & & & & \\
\hline Kindergarten Hyperactivity & & & 1.05 & 1.99 & 0 & 8 \\
\hline Kindergarten Inattention & & & 1.22 & 1.98 & 0 & 8 \\
\hline Kindergarten Conduct Problems & & & .64 & 1.49 & 0 & 8 \\
\hline Kindergarten Unsociability & & & .31 & .95 & 0 & 7 \\
\hline
\end{tabular}


Table 2

Descriptive statistics of the study variables at fifth grade

\begin{tabular}{|c|c|c|c|c|c|c|}
\hline Fifth grade variables & $\mathrm{N}$ & $\%$ & $\mathrm{M}$ & SD & Min & $\operatorname{Max}$ \\
\hline Sociodemographic background & 150 & & & & & \\
\hline Sex (boys) & & 51 & & & & \\
\hline Age & & & 10.77 & .33 & 10.08 & 11.42 \\
\hline \multicolumn{7}{|l|}{ Parents educational level } \\
\hline At least one parent has high school diploma & 59 & 39 & & & & \\
\hline \multicolumn{7}{|l|}{ Familial antecedents of reading difficulties } \\
\hline (cases reported) & 21 & 14 & & & & \\
\hline ODEDYS & 150 & & & & & \\
\hline Word Reading composite score & & & -.0006 & .84 & -2.56 & 1.41 \\
\hline Teachers' Questionnaire & 114 & & & & & \\
\hline Kindergarten Hyperactivity & & & .85 & 1.60 & 0 & 7 \\
\hline Fifth grade Hyperactivity & & & .95 & 1.82 & 0 & 8 \\
\hline Kindergarten Inattention & & & 1 & 1.71 & 0 & 8 \\
\hline Fifth grade Inattention & & & .97 & 1.65 & 0 & 7 \\
\hline Kindergarten Conduct Problems & & & .71 & 1.37 & 0 & 8 \\
\hline Fifth grade Conduct Problems & & & .66 & 1.32 & 0 & 7 \\
\hline Kindergarten Unsociability & & & .14 & .46 & 0 & 2 \\
\hline Fifth grade Unsociability & & & .40 & .91 & 0 & 4 \\
\hline
\end{tabular}


Table 3

Group differences between the children non-followed and followed from kindergarten through fifth grade according to sociodemographic and familial variables

\begin{tabular}{|c|c|c|c|c|c|}
\hline & Non-followed & Followed & & & \\
\hline & $\mathrm{N}(\%)$ & $\mathrm{N}(\%)$ & chi-square & $\mathrm{df}$ & $\mathrm{p}$ \\
\hline \multicolumn{6}{|l|}{ Sociodemographic background } \\
\hline \multicolumn{6}{|l|}{ Sex } \\
\hline Boys & $343(52.13)$ & $79(51.30)$ & .03 & 1 & .85 \\
\hline Girls & $315(47.87)$ & $75(48.70)$ & & & \\
\hline \multicolumn{6}{|l|}{ Parents educational level } \\
\hline One parent has high school diploma & $293(49.16)$ & $57(38.26)$ & 5.69 & 1 & .01 \\
\hline Both parents have high school diploma & $303(50.84)$ & $92(61.74)$ & & & \\
\hline \multicolumn{6}{|l|}{ Familial antecedents of reading } \\
\hline \multicolumn{6}{|l|}{ difficulties } \\
\hline Absent & $514(77.88)$ & $133(86.36)$ & 5.51 & 1 & .02 \\
\hline Present & $146(22.12)$ & $21(13.64)$ & & & \\
\hline
\end{tabular}


Table 4

Group differences between the children non-followed and followed from kindergarten through fifth grade according to the BSEDS composite score and teachers' ratings of behavioral problems

\begin{tabular}{|c|c|c|c|c|c|c|c|c|}
\hline & \multicolumn{3}{|c|}{ Non-followed } & \multicolumn{3}{|c|}{ Followed } & \multirow[b]{2}{*}{$\mathrm{t}$} & \multirow[b]{2}{*}{$\mathrm{p}$} \\
\hline & $\mathrm{M}$ & SD & $\mathrm{N}$ & $\mathrm{M}$ & SD & $\mathrm{N}$ & & \\
\hline \multicolumn{9}{|l|}{ BSEDS } \\
\hline Global composite score & 69 & .14 & 536 & .73 & .11 & 141 & -3.45 & .0006 \\
\hline \multicolumn{9}{|l|}{ Teachers' Questionnaire } \\
\hline Kindergarten Hyperactivity & 1.08 & 2.06 & 498 & .83 & 1.58 & 89 & 1.32 & .18 \\
\hline Kindergarten Inattention & 1.25 & 2.02 & 491 & 1.01 & 1.71 & 88 & 1.20 & .23 \\
\hline Kindergarten Conduct Problems & .61 & 1.52 & 501 & .73 & 1.36 & 89 & -.70 & .48 \\
\hline Kindergarten Unsociability & .33 & 1.01 & 499 & .13 & .45 & 88 & 3.03 & .003 \\
\hline
\end{tabular}


Table 5

Regression analysis of the BSEDS composite score at kindergarten

\begin{tabular}{|c|c|c|c|c|c|}
\hline & \multicolumn{5}{|c|}{ Kindergarten BSEDS composite } \\
\hline & $\mathrm{r}^{2}$ & $\beta$ & $S(B)$ & $\mathrm{t}$ & $\mathrm{p}$ \\
\hline \multicolumn{6}{|l|}{ (Step 1) } \\
\hline \multicolumn{6}{|l|}{ Teachers' Questionnaire } \\
\hline Kindergarten Hyperactivity & .20 & -.003 & .004 & -.61 & .54 \\
\hline Kindergarten Inattention & & -.03 & .004 & -8.07 & $<.0001$ \\
\hline Kindergarten Conduct Problems & & .01 & .005 & 2.07 & .04 \\
\hline Kindergarten Unsociability & & -.02 & .008 & -2.24 & .03 \\
\hline \multicolumn{6}{|l|}{ (Step 2) } \\
\hline \multicolumn{6}{|l|}{ Teachers' Questionnaire } \\
\hline Kindergarten Inattention & .20 & -.03 & .003 & -10.10 & $<.0001$ \\
\hline Familial antecedents of reading difficulties & & -.04 & .02 & -2.46 & .014 \\
\hline \multicolumn{6}{|l|}{ (Step 3) } \\
\hline \multicolumn{6}{|l|}{ Teachers' Questionnaire } \\
\hline Kindergarten Inattention & 25 & -.03 & .003 & -9.41 & $<.0001$ \\
\hline Familial antecedents of reading difficulties & . & -.03 & .01 & -2.05 & .04 \\
\hline Parents educational level & & .06 & .01 & 5.14 & $<.0001$ \\
\hline
\end{tabular}

r². R-square; ß. Parameter Estimate; S(ß). Parameter Estimate /Standard Error 
Table 6

Regression analysis of the ODEDYS word reading composite score at fifth grade

\begin{tabular}{|c|c|c|c|c|c|}
\hline & \multicolumn{5}{|c|}{ Fifth grade ODEDYS Word Reading composite } \\
\hline & $\mathrm{r}^{2}$ & $\beta$ & $\mathrm{S}(ß)$ & $\mathrm{t}$ & $\mathrm{p}$ \\
\hline \multicolumn{6}{|l|}{ (Step 1) } \\
\hline \multicolumn{6}{|l|}{ Teachers' Questionnaire } \\
\hline Fifth grade Inattention & .15 & -.15 & .05 & -3.24 & .002 \\
\hline Familial antecedents of reading difficulties & & -.43 & .20 & -2.10 & .04 \\
\hline \multicolumn{6}{|l|}{ (Step 2) } \\
\hline \multicolumn{6}{|l|}{ BSEDS subtests } \\
\hline Syllabic deletion & .18 & .06 & .02 & 2.56 & .012 \\
\hline Oral Comprehension & & .09 & .05 & 1.99 & .048 \\
\hline Letter reading & & .07 & .03 & 2.67 & .008 \\
\hline \multicolumn{6}{|l|}{ (Step 3) } \\
\hline \multicolumn{6}{|l|}{ BSEDS subtests } \\
\hline Syllabic deletion & & .05 & .02 & 2.29 & .02 \\
\hline Oral Comprehension & .20 & .08 & .05 & 1.69 & .09 \\
\hline Letter reading & & .06 & .02 & 2.62 & .009 \\
\hline Familial antecedents of reading difficulties & & -.42 & .20 & -2.13 & .04 \\
\hline \multicolumn{6}{|l|}{ (Step 4) } \\
\hline \multicolumn{6}{|l|}{ BSEDS subtests } \\
\hline Syllabic deletion & & .05 & .03 & 2.18 & .03 \\
\hline Oral Comprehension & .25 & .05 & .05 & 1.05 & .30 \\
\hline Letter reading & & .08 & .03 & 2.65 & .009 \\
\hline \multicolumn{6}{|l|}{ Teachers' Questionnaire } \\
\hline Fifth grade Inattention & & -.09 & .05 & -1.75 & .08 \\
\hline \multicolumn{6}{|l|}{ (Step 5) } \\
\hline \multicolumn{6}{|l|}{ BSEDS subtests } \\
\hline Syllabic deletion & .26 & .05 & .03 & 2.11 & .04 \\
\hline Letter reading & & .08 & .03 & 2.77 & .006 \\
\hline Familial antecedents of reading difficulties & & -.37 & .21 & -1.76 & .08 \\
\hline \multicolumn{6}{|l|}{ Teachers' Questionnaire } \\
\hline Fifth grade Inattention & & -.08 & .05 & -1.66 & .10 \\
\hline
\end{tabular}

$\mathrm{r}^{2}$. R-square; $\beta$. Parameter Estimate; S(ß). Parameter Estimate /Standard Error 
Table 7

Group differences between children with reading difficulties and normal readers at fifth grade according to sociodemographic and familial variables

\begin{tabular}{|c|c|c|c|c|c|}
\hline & $\begin{array}{c}\text { Reading } \\
\text { difficulties }\end{array}$ & $\begin{array}{l}\text { Normal } \\
\text { readers }\end{array}$ & & & \\
\hline & $\mathrm{N}(\%)$ & $\mathrm{N}(\%)$ & chi-square & df & $\mathrm{p}$ \\
\hline \multicolumn{6}{|l|}{ Sociodemographic background } \\
\hline \multicolumn{6}{|l|}{ Sex } \\
\hline Boys & $6(37.5)$ & $72(52.94)$ & 1.4 & 1 & .24 \\
\hline Girls & $10(62.5)$ & $64(47.06)$ & & & \\
\hline \multicolumn{6}{|l|}{ Parents educational level } \\
\hline One parent has high school diploma & $6(37.5)$ & $50(38.17)$ & .002 & 1 & .95 \\
\hline Both parents have high school diploma & $10(62.5)$ & $81(61.83)$ & & & \\
\hline \multicolumn{6}{|l|}{ Familial antecedents of reading } \\
\hline \multicolumn{6}{|l|}{ difficulties } \\
\hline Absent & $10(62.5)$ & $121(88.97)$ & 8.42 & 1 & .004 \\
\hline Present & $6(37.5)$ & $15(11.03)$ & & & \\
\hline
\end{tabular}


Table 8

Group differences between children with reading difficulties and normal readers at fifth grade according to the ODEDYS' subtests and teacher's ratings of inattention problems

\begin{tabular}{|c|c|c|c|c|c|c|c|c|c|}
\hline & \multicolumn{3}{|c|}{$\begin{array}{c}\text { Reading } \\
\text { difficulties }\end{array}$} & \multicolumn{3}{|c|}{$\begin{array}{l}\text { Normal } \\
\text { readers }\end{array}$} & \multirow[b]{2}{*}{$\mathrm{t}$} & \multirow[b]{2}{*}{$\mathrm{p}$} & \multirow[b]{2}{*}{ es } \\
\hline & $\mathrm{M}$ & $\overline{\mathrm{SD}}$ & $\mathrm{N}$ & $\bar{M}$ & SD & $\mathrm{N}$ & & & \\
\hline \multicolumn{10}{|l|}{ ODEDYS subtests } \\
\hline Syllabic deletion & 4.19 & 3.15 & 16 & 6.71 & 3.19 & 134 & -3.03 & .007 & .77 \\
\hline Oral Comprehension & 6.56 & 1.63 & 16 & 7.79 & 1.45 & 135 & -2.87 & .01 & .81 \\
\hline Letter reading & 4.31 & 2.27 & 16 & 6.19 & 2.79 & 131 & -3.04 & .006 & .68 \\
\hline \multicolumn{10}{|l|}{ Teachers' Questionnaire } \\
\hline Fifth grade Inattention & 1.87 & 2.26 & 15 & .80 & 1.48 & 102 & 1.76 & .09 & .65 \\
\hline
\end{tabular}




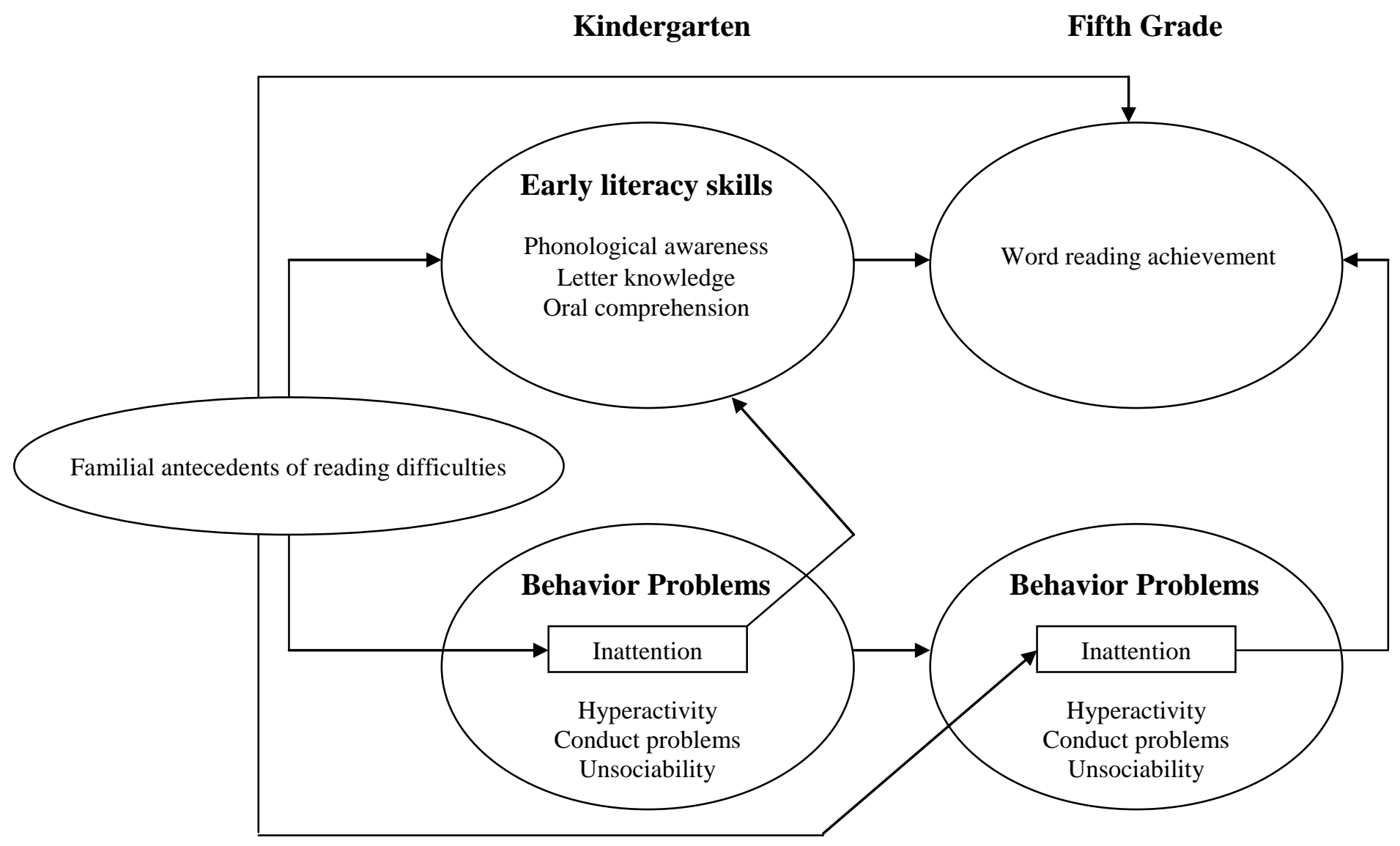

Figure 1. General model for analysis: Relations among emergent literacy skills, familial antecedents of reading difficulties, behavioral problems, and word reading. 